\title{
New Horizons for the Roles and Association of APEI/Ref-I and ABCAI in Atherosclerosis
}

\author{
Wujun Chen' \\ Shuai Wang ${ }^{2}$ \\ Dongming Xing ${ }^{1,3}$ \\ 'Cancer Institute, The Affiliated Hospital \\ of Qingdao University, Qingdao \\ University, Qingdao Cancer Institute, \\ Qingdao, Shandong, 26607I, People's \\ Republic of China; ${ }^{2}$ School of Medical \\ Imaging, Radiotherapy Department of \\ Affiliated Hospital, Weifang Medical \\ University, Weifang, Shandong, 261053, \\ People's Republic of China; ${ }^{3}$ School of \\ Life Sciences, Tsinghua University, Beijing, \\ I00084, People's Republic of China
}

Correspondence: Dongming Xing Cancer Institute, The Affiliated Hospital of Qingdao University, Qingdao University, Qingdao Cancer Institute, Qingdao, Shandong, People's Republic of China

Tel +86-532-82991017

Email xdm_tsinghua@।63.com

Shuai Wang

School of Medical Imaging, Radiotherapy

Department of Affiliated Hospital,

Weifang Medical University, Weifang,

Shandong, People's Republic of China

Tel +86-536-8462228

Email sdwftcmws@163.com

\begin{abstract}
Atherosclerosis is the leading cause of death worldwide. APE1/Ref-1 and ABCA1 play key roles in the progression of atherosclerosis. APE1/Ref-1 suppresses atherosclerosis via multiple mechanisms, including reducing the IL-6-, TNF- $\alpha-$, and IL-1 $\beta-$ mediated proinflammatory responses, suppressing ROS-mediated oxidant activity and Bax/ Bcl-2-mediated vascular calcification and apoptosis, and reducing LOX-1-mediated cholesterol uptake. However, APE1/Ref-1 also promotes atherosclerosis by increasing the activity of the NK- $\kappa$ B and S1PR1 pathways. APE1/Ref-1 localizes to the nucleus, cytoplasm, and mitochondria and can be secreted from the cell. APE1/Ref-1 localization is dynamically regulated by the disease state and may be responsible for its proatherogenic and antiatherogenic effects. ABCA1 promotes cholesterol efflux and anti-inflammatory responses by binding to apoA-I and regulates apoptotic cell clearance and HSPC proliferation to protect against inflammatory responses. Interestingly, in addition to mediating these functions, ABCA1 promotes the secretion of acetylated APE1/Ref-1 (AcAPE1/Ref-1), a therapeutic target, which protects against atherosclerosis development. The APE1/Ref-1 inhibitor APX3330 is being evaluated in a phase II clinical trial. The LXR agonist LXR-623 (WAY252623 ) is an agonist of ABCA1 and the first LXR-targeting compound to be evaluated in clinical trials. In this article, we review the roles of ABCA1 and APE1/Ref-1 in atherosclerosis and focus on new insights into the ABCA1-APE1/Ref-1 axis and its potential as a novel therapeutic target in atherosclerosis.
\end{abstract}

Keywords: atherosclerosis, inflammatory, APE1/Ref-1, ABCA1, cholesterol efflux

\section{Introduction}

Myocardial infarction (MI) due to coronary artery disease (CAD) is a leading cause of morbidity and mortality worldwide. Atherosclerosis is the main cause of CAD and MI. ${ }^{1-3}$ The major characteristic of the underlying pathology of atherosclerosis is a bidirectional interaction between lipids and inflammation. Atherosclerosis occurs during foam cell generation, a process regulated by balancing the lipid uptake and efflux rates. ${ }^{4}$ Lipid efflux is mainly controlled by ATP-binding cassette transporter A1 (ABCA1). ${ }^{5,6}$ Previous studies from our laboratory and others have shown that ABCA1 promotes cholesterol efflux and anti-inflammatory responses by binding to apolipoprotein A-I (apoA-I), suggesting that ABCA1 may be a therapeutic target for atherosclerosis. ${ }^{7-11}$

Apurinic (apyrimidinic) endonuclease-1/redox factor-1 (APE1/APE1/Ref-1), a $37-\mathrm{kDa}$ protein, is a ubiquitously expressed bifunctional protein involved in the oxidative stress response, DNA damage repair, and facilitation of the DNA-binding activities of many redox-sensitive transcription factors, including activator protein- 
1 (AP-1) and nuclear factor $\kappa \mathrm{B}(\mathrm{NF}-\kappa \mathrm{B})$. APE1/Ref-1 is known to participate in a variety of redox-mediated events that regulate cell growth, differentiation, survival, and death. ${ }^{12,13}$ Many studies have shown that APE1/Ref-1 is a therapeutic target for vascular inflammation and a serological biomarker of CAD. ${ }^{14}$ Interestingly, in addition to mediating cholesterol efflux, ABCA1 promotes the secretion of acetylated APE1/Ref-1 (AcAPE1/Ref-1) and forms the ABCA1-APE1/Ref-1 axis. ${ }^{15,16}$ Accumulating evidence has shown that APE1/Ref-1 plays dual roles in atherosclerosis, as it can have both proatherogenic and antiatherogenic effects. ${ }^{17,18}$ However, AcAPE1/Ref-1 secretion may protect against the development of atherosclerosis, suggesting that ABCA1 promotes AcAPE1/Ref1 secretion and protects against atherosclerosis development. ${ }^{19}$ Although ABCA1 mediates the release of AcAPE1/Ref-1, the effect of this function on atherosclerosis is not clear. In this article, we review the roles of APE1/Ref-1 and ABCA1 in atherosclerosis and focus on new insight into the ABCA1-APE1/Ref-1 axis and drugs targeting its components.

\section{Roles of APEI/Ref-I and ABCAI in Atherosclerosis Dual Roles of APEI/Ref-I in Atherosclerosis}

APE1/Ref-1 was shown to be upregulated in human atherosclerotic plaques. ${ }^{20}$ Moreover, hypercholesterolemia has been associated with the increased expression of the base excision repair (BER)-specific DNA repair enzyme APE1/ Ref-1. A high-fat diet further increased total APE1/Ref-1 protein expression in apoE-/- mice. ${ }^{21}$ Thus, APE1/Ref-1 has been shown to be associated with the development of atherosclerosis. However, the role of APE1/Ref-1 in atherosclerosis is twofold. APE1/Ref-1 accelerates the progression of atherosclerosis by promoting the secretion of M1 macrophage-mediated proinflammatory cytokines and suppresses the development of atherosclerosis by reducing inflammation and promoting tissue repair.

\section{APEI/Ref-I as an Antiatherogenic Factor}

APE1/Ref-1 is involved in DNA damage repair. ${ }^{22}$ Oxidative tissue injury is aggravated during plaque formation, and increased reactive oxygen species (ROS) production and DNA damage in monocytes are biomarkers of aging and atherosclerosis. ${ }^{23,24}$ APE1/Ref-1 is present throughout the entire plaque. ${ }^{20}$ APE1/Ref-1 is upregulated in plaques in carotid arteries, suggesting that APE1/Ref-1 protects against atherosclerosis by repairing DNA damage and oxidative tissue injury. Vascular calcification is linked to plaque instability and contributes to increased cardiovascular mortality and poor cardiovascular outcomes for patients. $^{25,26}$ APE1/Ref-1 was reported to inhibit vascular calcification in vascular smooth muscle cells (VSMCs) and in rat aortas cultured ex vivo. ${ }^{18}$ Moreover, APE1/ Ref-1 was shown to reduce vascular calcification, antioxidant activity, and antiapoptotic activity by suppressing ROS production and reducing the $\mathrm{Bax} / \mathrm{Bcl}-2$ ratio. However, the APE1/Ref-1 redox mutant did not reduce calcification, suggesting that APE/Ref-1-mediated redox activity protects against vascular calcification and atherosclerosis development. ${ }^{18}$ In particular, APE1/Ref-1 reduces intracellular ROS production. ${ }^{27,28}$ APE1/Ref-1 suppressed monocyte adhesion by reducing vascular cell adhesion molecule-1 (VCAM-1) expression in a manner dependent on the inhibition of superoxide production and p38 MAPK activation in tumor necrosis factor $\alpha$ (TNF- $\alpha)$ stimulated human umbilical vein endothelial cells (HUVECs). ${ }^{29}$ APE1/Ref-1 was shown to exert anti-inflammatory effects by reducing the activity of thiol-disulfide exchanges $^{19}$ and to suppress hypoxia-induced EC apoptosis. ${ }^{30}$ Furthermore, APE1/Ref-1 suppressed balloon injury-induced neointimal formation in rats, ${ }^{31}$ suggesting that APE1/Ref-1 exhibits anti-inflammatory functions in the vascular endothelium. APE1/Ref- $1 \pm$ mice exhibit cardiovascular diseases such as hypertension. APE1/Ref-1 decreased ox-LDL-induced inflammatory molecules, including interleukin (IL)-6, TNF- $\alpha$ and IL-1 $\beta$, in macrophages. $^{32}$ In addition, APE1/Ref-1 reduced oxLDL uptake and foam cell formation from macrophages by hindering binding of the transcription factor OCT1 to the LOX-1 promoter. $^{32}$ Thus, APE1/Ref-1 protects against atherosclerosis by prohibiting inflammation, reducing vascular calcification and cholesterol uptake, and repairing DNA damage and oxidative tissue injury.

\section{APEI/Ref-I as a Proatherogenic Factor}

Angiotensin II (Ang II) is a major mediator of inflammation and VSMC migration and proliferation. ${ }^{33}$ Chronic or long-term exposure to Ang II may accelerate the development of atherosclerosis. ${ }^{34,35}$ Interestingly, Ang II caused the translocation of APE1/Ref-1 from the cytoplasm to the nucleus in rat aortic smooth muscle cells (RASMCs). ${ }^{17}$ Ang II also stimulated migration and sphingosine-1-phosphate receptor (S1PR1) expression by increasing the 
binding of APE1/Ref-1 to the S1PR1 promoter in RASMCs and rats. ${ }^{17}$ S1PR1 activation is responsible for VSMC migration, apoptosis, and proliferation, resulting in vascular restenosis and neointima formation, ${ }^{36,37}$ suggesting that APE1/Ref-1 contributes to the advancement of neointima plaque formation and atherosclerosis development by binding the S1PR1 promoter. Dai et al found that homocysteine (Hcy) increased ROS production by upregulating NADPH oxidase-mediated APE1/Ref-1 expression; moreover, they showed that APE1/Ref-1 increased NF- $\kappa \mathrm{B}$ activity and monocyte chemoattractant protein-1 (MCP-1) secretion by binding to the promoter in mouse and human macrophages, thereby accelerating atherosclerosis development in apoE-/- mice. ${ }^{38}$ Consistently, hyperhomocysteinemia (HHcy) has been shown to be an independent risk factor for atherosclerosis, suggesting that Hcy accelerates atherosclerosis development by increasing APE1/Ref-1 expression. ${ }^{38,39}$ Chen et al found that thioredoxin 1 ( Trx1) decreases the expression and secretion of MCP-1 by suppressing APE1/Ref-1 in vascular endothelial cells (ECs). ${ }^{40}$ Hadri et al reported that Trx-1 reduces the expression of proinflammatory M1 macrophage markers, such as TNF- $\alpha$ and MCP-1, in human monocyte-derived macrophages and murine peritoneal macrophages by reducing APE1/Ref-1 expression. ${ }^{41}$ M1 macrophages are oriented to produce proinflammatory cytokines such as IL-1 $\beta$, IL-6, and TNF- $\alpha$. M2 macrophages mostly resolve inflammation and promote tissue remodeling through the expression of factors such as arginase-1 (Arg-1), transforming growth factor (TGF)- $\beta$, and IL-10. ${ }^{42,43}$ Trx 1 decelerates the progression of atherosclerosis by blunting M1 macrophage polarization and proinflammatory factor expression, ${ }^{44-46}$ suggesting that Trx1 antagonizes atherosclerosis by reducing APE1/Ref-1 expression. Taken together, these results suggest that APE1/Ref-1 accelerates atherosclerosis development by stimulating NF- $\kappa$ B expression and M1 macrophage polarization (Figure 1).

\section{Potential Roles of AcAPEI/Ref-I in Atherosclerosis}

Acetylation, a type of posttranslational modification, regulates the function of multiple cytoplasmic proteins involved in cell survival, proliferation, and death as well as disease-related signaling. ${ }^{47,48}$ APE1/Ref-1 acetylation controls multiple biological functions. ${ }^{49}$ Apurinic/apyrimidinic (AP) sites are the most common forms of genomic DNA damage, and many studies have shown that AP sites are repaired by APE1/Ref- $1 .{ }^{50}$ In the absence of APE1/Ref-1 acetylation, AP sites accumulate in the genome, evoking increased cellular sensitivity to DNAdamaging agents, suggesting that APE1/Ref-1 acetylation plays a key role in cell survival and/or proliferation in response to genotoxic stress. ${ }^{51,52}$ Extracellularly secreted APE1/Ref-1 inhibits TNF- $\alpha$-stimulated endothelial inflammation and lipopolysaccharide (LPS)induced cytokine production in response to intracellular acetylation. ${ }^{53}$ An anti-APE1/Ref-1 antibody was shown to rapidly prevent APE1/Ref-1 acetylation-mediated anti-inflammatory signals. ${ }^{19}$ Importantly, AcAPE1/Ref1 is a cancer therapeutic target. ${ }^{54}$ These results suggest that AcAPE1/Ref-1 secretion protects against atherosclerosis development via anti-inflammatory and DNA damage repair mechanisms.

\section{APEI/Ref-I is a Potential CAD Biomarker}

Increasing evidence indicates that APE1/Ref-1 is a potential biomarker of CAD. In animal experiments, APE1/Ref1 was increased in the aorta and blood of apoE-/- mice fed a Western diet (WD). ${ }^{55}$ Interestingly, APE1/Ref-1 expression in aortic tissue was significantly positively correlated with VCAM-1, a vascular inflammation marker, and galectin-3, a macrophage marker, in apoE-/- mice. Plasma APE1/Ref-1 levels were also shown to be significantly positively correlated with the neutrophil/lymphocyte ratio (NLR) ( $\mathrm{r}=0.79)$, a marker of systemic inflammation. The cutoff value for APE1/Ref-1 to predict atherosclerotic inflammation was $4.903 \mathrm{ng} / \mathrm{mL}$, with $100 \%$ sensitivity and $91 \%$ specificity, suggesting that APE1/Ref-1 is a potential biomarker of atherosclerotic inflammation. ${ }^{55}$ In clinical studies, APE1/Ref-1 was shown to be increased in human atherosclerotic plaques. Serum APE1/Ref-1 levels were higher in $303 \mathrm{CAD}$ patients than in 57 control patients $(0.63 \pm 0.07$ vs $0.12 \pm 0.07 \mathrm{ng} / 100 \mu \mathrm{L}$, respectively; $\mathrm{p}<0.01)$. Moreover, serum APE1/Ref-1 levels were higher in $175 \mathrm{MI}$ patients than in 128 angina patients $(0.81 \pm 0.10$ vs $0.38 \pm 0.11 \mathrm{ng} / 100 \mu \mathrm{L}$, respectively; $\mathrm{p}<0.01) .{ }^{14}$ Correlation analysis revealed that the serum levels of APE1/Ref-1 were positively correlated with other cardiovascular biomarkers, including troponin I $(\mathrm{r}=0.222$; $\mathrm{p}<0.0001)$ and $\mathrm{N}$-terminal pro-B type natriuretic peptide (NT-proBNP, r=0.217; $\mathrm{p}<0.0001$ ) but were not highly sensitive to C-reactive protein (CRP). APE1/Ref-1 levels were also shown to be negatively correlated with the ejection fraction $(\mathrm{EF}, \mathrm{r}=-0.221 ; \mathrm{p}=0.002) .{ }^{14}$ Nevertheless, the $P$-value of the APE1/Ref-1 single nucleotide polymorphism (SNP) rs1878703 in 1624 patients with MI compared with 4087 age- and sex-matched controls was 


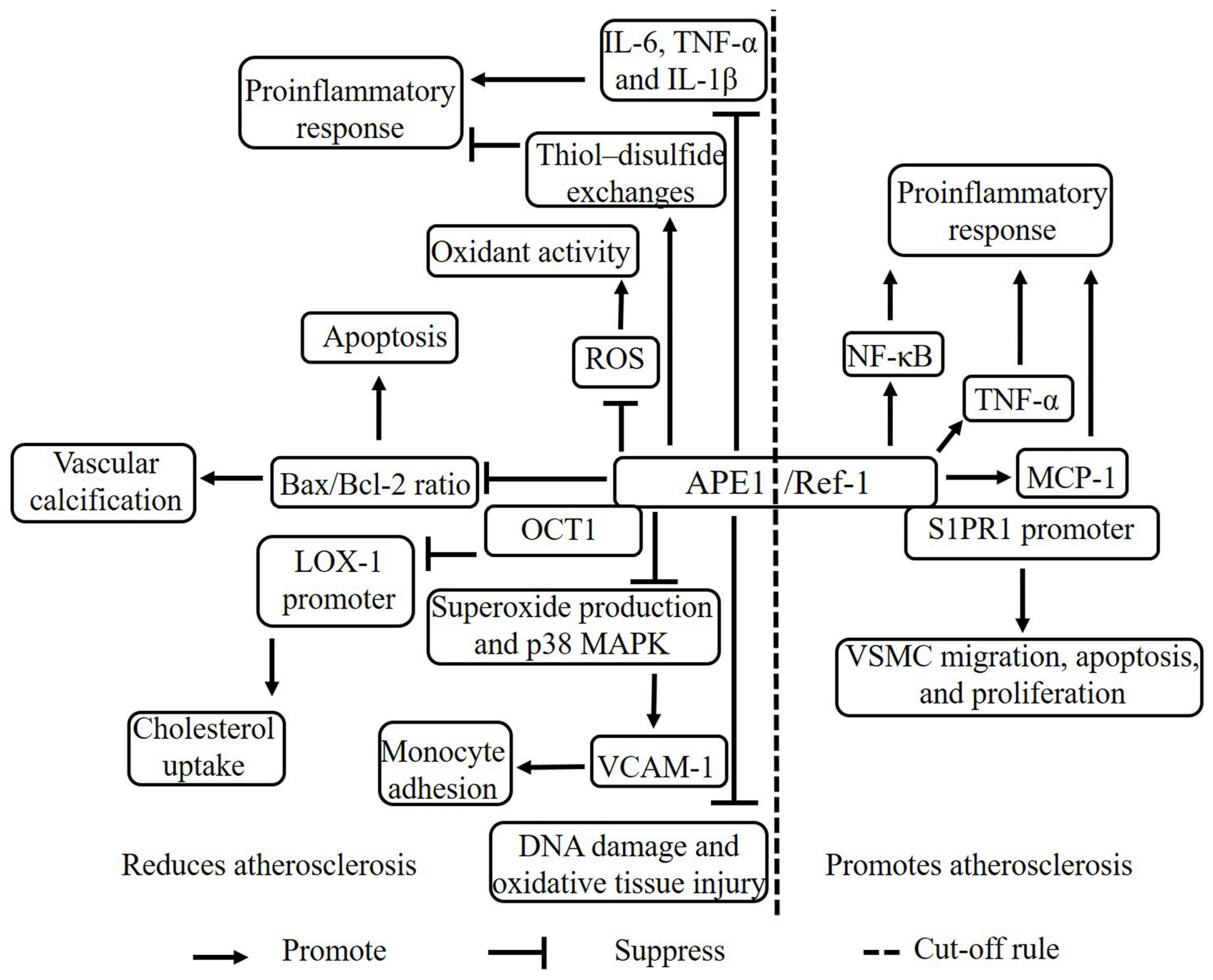

Figure I The mechanism of APEI/Ref-I in atherosclerosis. APEI/Ref-I has both proatherogenic and antiatherogenic effects. APEI/Ref-I suppresses atherosclerosis via multiple mechanisms. APEI/Ref-I reduces the proinflammatory response by increasing thiol-disulfide exchanges and suppressing the expression of IL- 6 , TNF- $\alpha$, and IL-I $\beta$. APEI/Ref-I reduces oxidant activity by suppressing ROS levels and decreases vascular calcification and apoptosis by suppressing the Bax/Bcl-2 ratio. APEI/Ref-I reduces cholesterol uptake by binding OCTI to inhibit activation of the LOX-I promoter. APEI/Ref-I decreases monocyte adhesion by suppressing superoxide production and $\mathrm{P} 38$ MAPK expression to restrain VCAM-I. APEI/Ref-I reduces DNA damage and oxidative tissue injury. APEI/Ref-I promotes atherosclerosis via multiple mechanisms. APEI/ Ref-I increases the proinflammatory response by increasing NK- $\mathrm{B}$ p pathway signaling and TNF- $\alpha$ and MCP-I expression. APEI/Ref-I promotes VSMC migration, apoptosis, and proliferation by binding the SIPRI promoter.

0.09 ( $p>0.05)$, suggesting that this APE1/Ref-1 SNP is not associated with the risk of MI $(\mathrm{p}=0.09) .{ }^{56}$ In addition, APE1/Ref-1 serum levels were not correlated with the severity of myocardial injury, unlike the correlations with peak troponin I and peak CK-MB expression. ${ }^{14}$ However, serum APE1/Ref-1 levels were positively correlated with the degree of inflammation and myocarditis score in the heart of mice infected with the CVB3 virus $(r=0.750, p<$ 0.01), suggesting that serum APE1/Ref-1 levels can be used to assess myocardial injury in the context of viral myocarditis. ${ }^{57}$ Therefore, APE1/Ref-1 is a potential biomarker of CAD and is, at the very least, a potential biomarker of vessel damage. However, despite numerous studies on this biomarker, its value in clinical translation is still being investigated.

\section{Role of ABCAI in Atherosclerosis}

ABCA1 is a key mediator of intracellular cholesterol efflux to apoA-I for the generation of high-density lipoprotein (HDL), which protects against atherosclerotic vascular diseases by transferring cholesterol from peripheral cells to the liver for biliary excretion, constituting the process of reverse cholesterol transport (RCT). ${ }^{58-60}$ Previous studies by our laboratory and others have demonstrated that ABCA1 plays a critical role in preventing cholesterol accumulation in macrophages, 
while deficiency or mutation of this transporter lead to defects in cholesterol efflux and an increased risk of atherosclerosis. $^{10,11,15,61-65}$ Several studies have shown that $\mathrm{ABCA} 1$ reduces inflammatory responses by inhibiting the NF- $\kappa$ B signaling pathway via the removal of ROS. ${ }^{8,66}$ High cholesterol and inflammatory signals promote HSPC proliferation and preferential differentiation to enhance vascular inflammation and atherosclerosis progression. ${ }^{67}$ ABCA1 suppressed HSPC proliferation and extramedullary hematopoiesis by reducing the expression of the common $\beta$ subunit of the receptor for granulocyte macrophage colony-stimulating factor (GM-CSF) and IL-3, ${ }^{68}$ suggesting a mechanism by which ABCA1 suppresses vascular inflammation.

Previous studies by our laboratory and others have also demonstrated that ABCA1 complexed with apoA-I plays a critical role in anti-inflammatory activities. ${ }^{8,61,62,69,70}$ ABCA1 also regulates the secretion of various proteins, such as macrophage migration inhibitory factor (MIF), ${ }^{71}$ IL- $1 \beta,{ }^{72}$ apoE, ${ }^{73}$ and annexin A1 (ANXA1), ${ }^{74}$ the latter of which is associated with anti-inflammatory responses. We found that ABCA1 and ANXA1 may form a feedback loop and regulate each other. ${ }^{74}$ However, the crosstalk between ABCA1 and ANXA1 in atherosclerosis has not been investigated. ApoA-I and apoE decreased the development of atherosclerosis by enhancing cholesterol efflux and antiinflammatory effects in macrophage cultures and in vivo. Importantly, ABCA1 is a key regulator of apoA- $\mathrm{I}^{75}$ and apoE lipidation. ${ }^{76}$ Furthermore, ABCA1, apoA-I, and apoE are coexpressed in macrophages, implying that ABCA1 also protects against atherosclerosis by enhancing apoA-I- and apoE-mediated antiatherogenic effects. ABCA1 also mediates microparticle ${ }^{77-79}$ and exosome secretion. ${ }^{79,80}$ Microparticles, which encompass exosomes, nanoparticles, and shedding vesicles, are not only prognostic markers of atherosclerosis acceleration but also a clinical manifestation of familial hypercholesterolemia. ${ }^{81-83}$ Therefore, ABCA1 may regulate atherosclerosis development by mediating the secretion of exosomes and microparticles.

Many studies have demonstrated that the impaired clearance of apoptotic cells promotes the development of atherosclerosis. Apoptotic cell clearance is also termed programmed cell removal (PrCR) or efferocytosis and mainly involves the following stages: (1) "find me", (2) "eat me", (3) and endocytosis. ${ }^{84,85}$ ABCA1 also promotes the apoptotic cell clearance process. ${ }^{86}$ ABCA1 promotes efferocytosis by regulating the release of "find me" ligands, including LPC, and the exposure, release, and expression of "eat me" ligands, including phosphatidylserine (PtdSer), ANXA1, ANXA5, multiple EGF-like domains 10 (MEGF10), and engulfment adaptor phosphotyrosine-binding domain (PTB) domain containing 1 (GULP1). ${ }^{74,87,88}$ ABCA1 engages a pathway similar to that of transglutaminase 2 (TG2), an "eat me" ligand. ${ }^{89}$ Interestingly, apoptotic cell clearance increases ABCA1 expression, but the mechanism is unclear. ABCA1 can form several regulatory feedback axes with ANXA1, MEGF10, and GULP1, suggesting that apoptotic cell clearance increases ABCA1 expression by enhancing the expression of ANXA1, MEGF10, and GULP1. However, further studies are needed to clearly elucidate these axes. Taken together, these results suggest that ABCA1 protects against atherosclerosis by enhancing cholesterol efflux, anti-inflammatory effects, autophagy, apoptotic cell clearance, and microparticle and exosome secretion (Figure 2).

\section{The ABCAI-APEI/Ref-I Axis: New Insight into Atherosclerosis The ABCAI-APEI/Ref-I Axis: ABCAI Promotes APEI/Ref-I Secretion}

Recently, ABCA1 was shown to promote APE1/Ref-1 secretion. ${ }^{16}$ The histone deacetylase (HDAC) inhibitor trichostatin A (TSA) did not regulate APE1/Ref-1 secretion. However, glyburide, which inhibits the expression of $\mathrm{ABC}$ transporters, including $\mathrm{ABCA} 1, \mathrm{ABCB} 1, \mathrm{ABCB} 11$, $\mathrm{ABCC} 1, \mathrm{ABCC} 2, \mathrm{ABCC} 3, \mathrm{ABCC} 8$, and $\mathrm{ABCC}$, inhibited butyrate-induced APE1/Ref-1 secretion. ${ }^{16,90}$ Butyrate also increased ABCA1 expression, ${ }^{65,91}$ suggesting that butyrate promotes APE1/Ref-1 secretion by inducing ABCA1 expression and that glyburide suppresses butyrate-induced APE1/Ref-1 secretion by reducing ABCA1 expression. Specific knockdown of ABCA1 without affecting the expression of other $\mathrm{ABC}$ transporters, including $\mathrm{ABCB} 1, \mathrm{ABCC} 1, \mathrm{ABCC} 2$, and $\mathrm{ABCC} 8$, significantly inhibited APE1/Ref-1 secretion. Importantly, knockdown of other $\mathrm{ABC}$ transporters, including $\mathrm{ABCB} 1, \mathrm{ABCC} 1$, $\mathrm{ABCC} 2$, and $\mathrm{ABCC} 8$, did not regulate $\mathrm{APE} 1 /$ Ref-1 secretion, suggesting that ABCA1 plays a central role in APE1/ Ref-1 secretion. Mutating the acetylation sites in APE1/ Ref-1 (K6/K7R) has been shown to reduce colocalization with ABCA1. ABCA1 promotes APE1/Ref-1 secretion by binding to acetylated regions of APE $1 /$ Ref-1, suggesting that the extracellular secretion of APE1/Ref-1 depends on its acetylation. ${ }^{16}$ Taken together, the evidence suggests that 
Reduces atherosclerosis

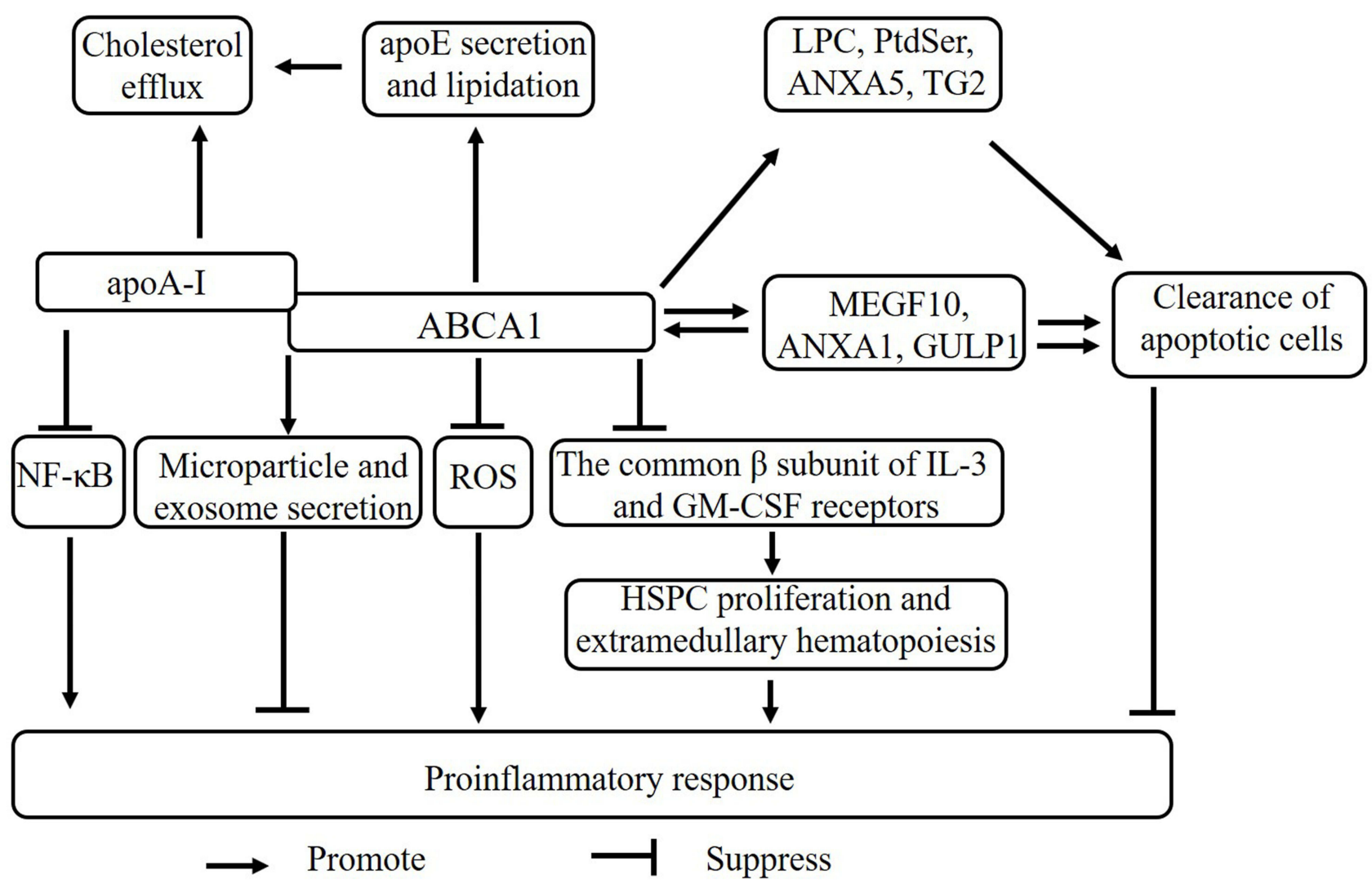

Figure 2 The mechanism of $A B C A I$ in atherosclerosis. $A B C A I$ promotes cholesterol efflux by binding to apoA-I and enhancing apoE secretion and lipidation. $A B C A I$ suppresses the proinflammatory response via multiple mechanisms, including promoting microparticle and exosome secretion; binding to apoA-I to reduce the NF- $\mathrm{B}$ pathway; promoting LPC, PtdSer, ANXAI, ANXA5, MEGFI0, GULPI, and TG2 expression to enhance apoptotic cell clearance; suppressing ROS levels; and reducing the common $\beta$ subunit of GM-CSF and IL-3 receptor-mediated HSPC proliferation and extramedullary hematopoiesis. ABCAI can form several regulatory feedback axes with ANXAI, MEGFI0, and GULPI. Apoptotic cell clearance increases cholesterol efflux and anti-inflammatory activities by enhancing ABCAI expression.

AcAPE1/Ref1 secretion mainly depends on the ABCA1 transporter, which promotes APE1/Ref-1 secretion and forms the ABCA1-APE1/Ref-1 axis.

\section{Potential Association Between ABCAI and APEI/Ref-I in Atherosclerosis}

As mentioned above, the secretion of AcAPE1/Ref-1 protects against atherosclerosis development via antiinflammatory and DNA damage repair mechanisms. ABCA1 controls the secretion of AcAPE1/Ref-1 and forms the ABCA1-APE1/Ref-1 axis. ABCA1 is also a therapeutic target in atherosclerosis. ABCA1 is expressed in macrophages and ECs and promotes cholesterol efflux to apoA-I. APE1/Ref-1 is also expressed in macrophages and ECs. ${ }^{55}$ Thus, ABCA1 promotes the secretion of AcAPE1/Ref-1 and might protect against the development of atherosclerosis. However, the effect of these activities on atherosclerosis is unclear, and more studies are needed.

\section{The ABCAI-APEI/Ref-I Axis as a Drug Target Drugs Targeting ABCAI}

DrugBank (https://go.drugbank.com/drugs) shows that ABCA1 is the target of drugs including ATP, glyburide, probucol, tocofersolan, vitamin E, and tamoxifen. Drugs approved for cardiometabolic diseases, including metformin, atorvastatin and rosuvastatin, may affect ABCA1 function. Metformin promotes cholesterol efflux and attenuates atherosclerotic plaques by enhancing the FGF21-ABCA1/ ABCG1 axis. $^{92}$ Atorvastatin induces cholesterol efflux by regulating the RhoA-PPAR $\gamma / \mathrm{LXR} \alpha-\mathrm{ABCA} 1$ axis, ${ }^{93}$ and rosuvastatin promotes cholesterol efflux by regulating the miR-33b-5p-ABCA1 axis. $^{94}$ Moreover, LXR agonists, 
including T0901317, GW3965, GW6340, IMB-808, 22(R)hydroxycholesterol (22(R)-HC), and LXR-623, promote cholesterol efflux and protect against atherosclerosis by binding the LXR target gene ABCA1 (Table 1). The administration of T0901317 or GW3965, first-generation LXR agonists, reduces plaque formation in mice, but neither T0901317 nor GW3965 is clinically useful due to the unwanted side effects of hepatic steatosis and hypertriglyceridemia. ${ }^{95}$ GW6340, an intestine-specific LXR agonist, increased macrophage ABCA1 expression and RCT efficiency but did not increase plasma triglyceride (TG) levels. ${ }^{96}$ IMB-808, a newly developed LXR agonist, promoted ABCA1 expression and cholesterol efflux and did not induce lipogenesis in HepG2 cells. ${ }^{97}$ 22(R)-HC, an

Table I ABCAI is a Therapeutic Drug Target

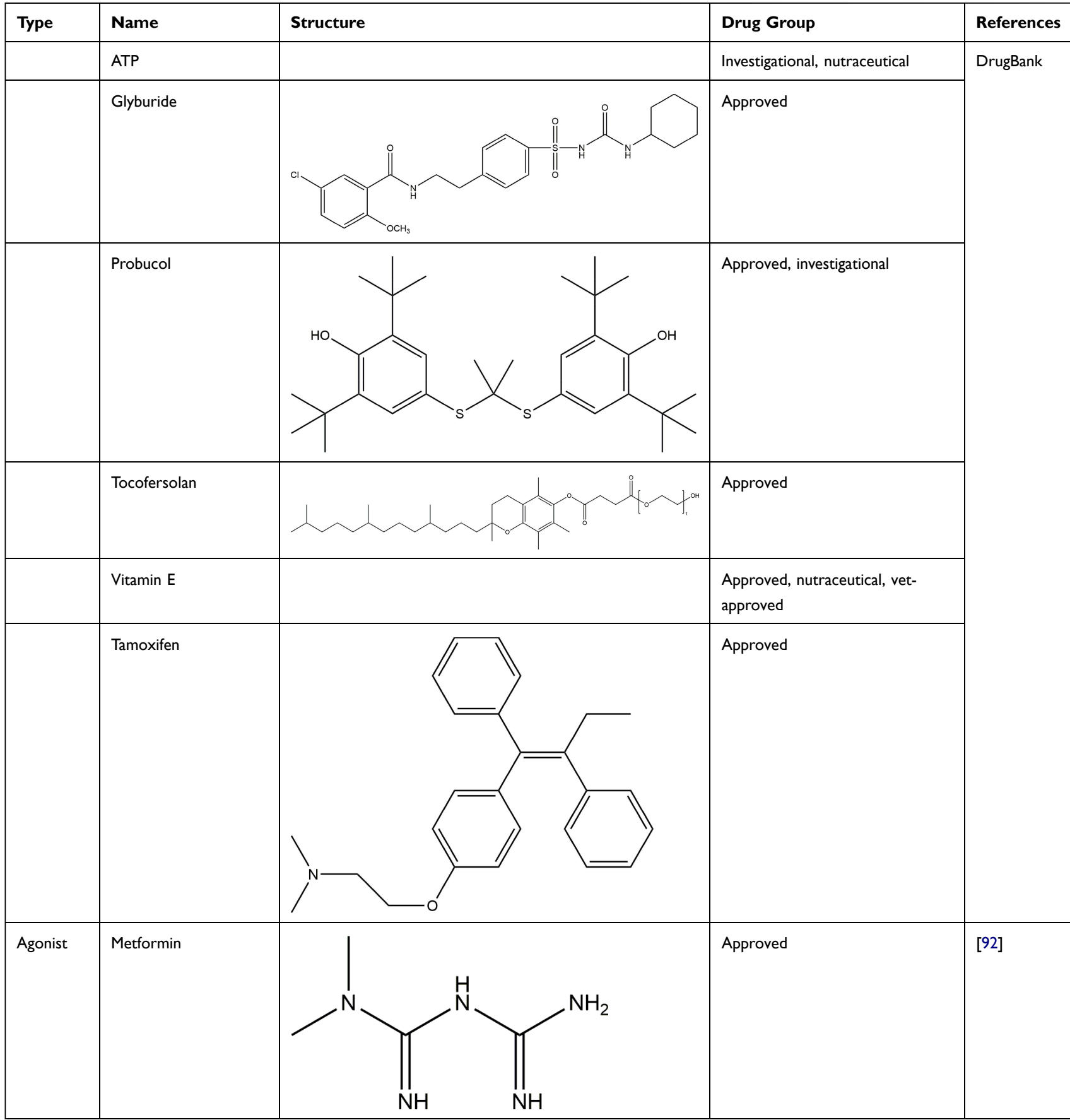

(Continued) 
Table I (Continued).

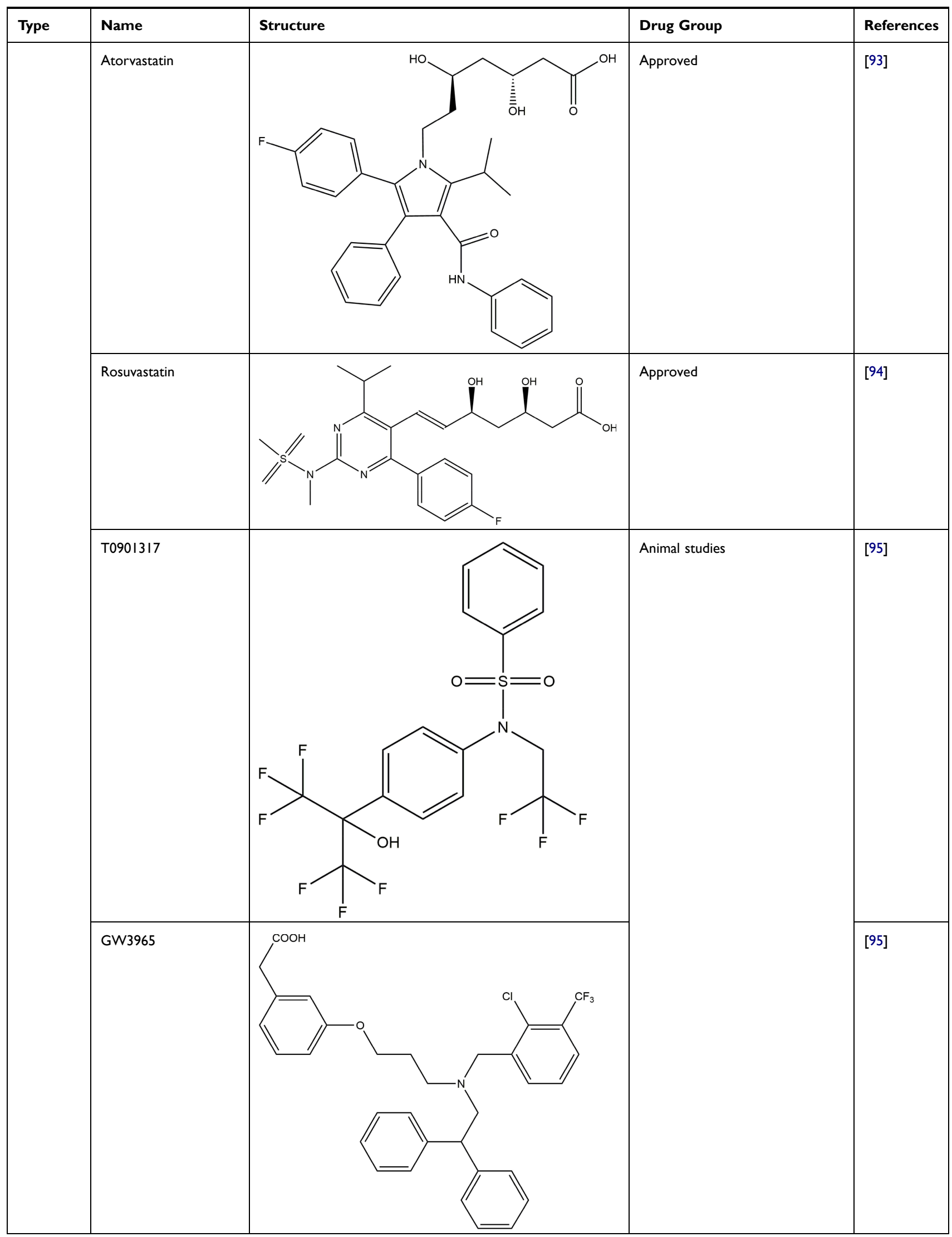

(Continued) 
Table I (Continued).

\begin{tabular}{|c|c|c|c|c|}
\hline Type & Name & Structure & Drug Group & References \\
\hline & GW6340 & & & [96] \\
\hline & IMB-808 & & & [97] \\
\hline & $\begin{array}{l}22(\mathrm{R})- \\
\text { Hydroxycholesterol }\end{array}$ & & & [98] \\
\hline & LXR-623 & & Investigational & [99] \\
\hline Antagonist & TPHP & $\mathrm{NH}_{2}$ & Animal studies & [100] \\
\hline
\end{tabular}

(Continued) 
Table I (Continued).

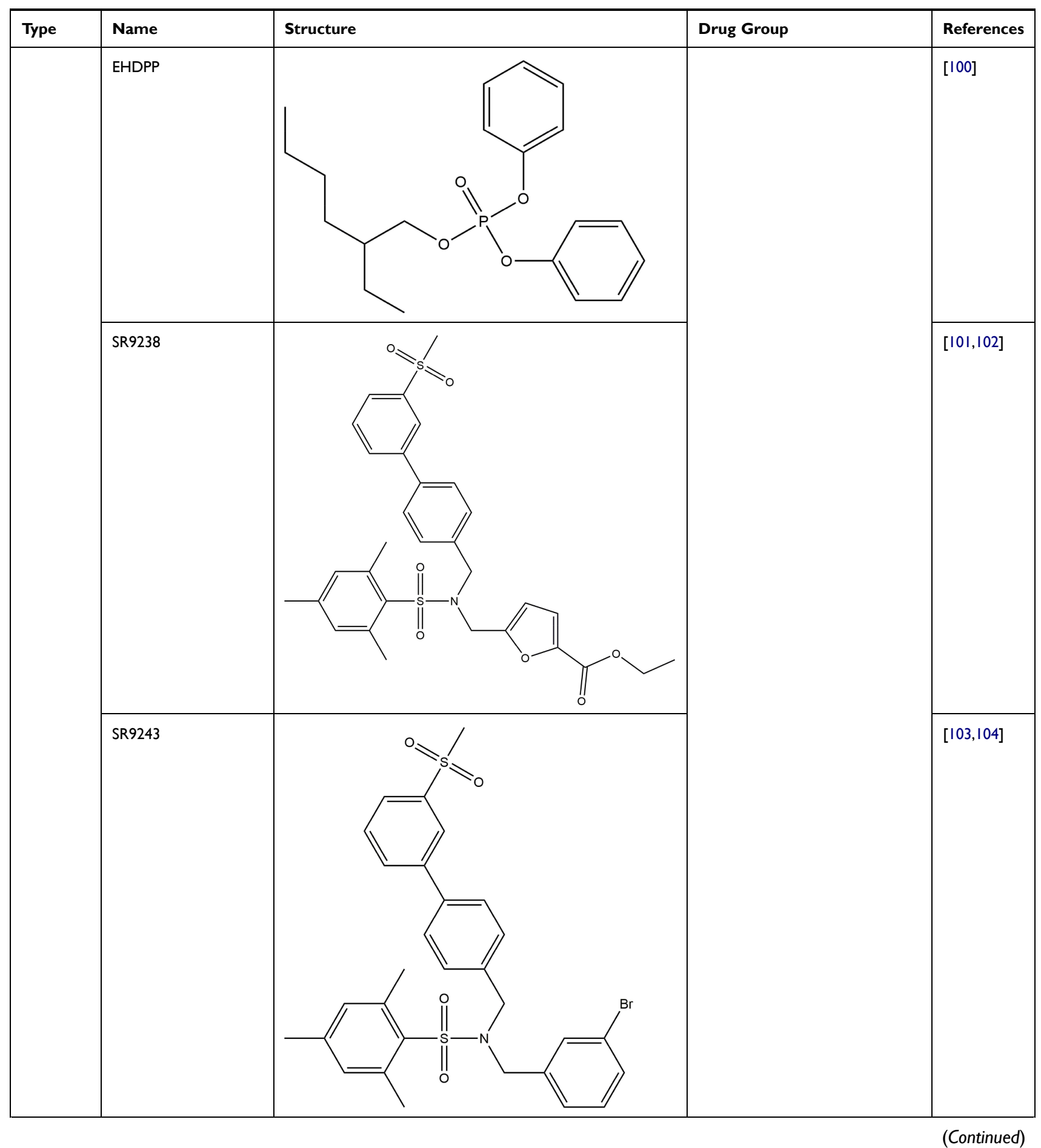


Table I (Continued).

\begin{tabular}{|l|l|l|l|l|}
\hline Type & Name & Structure & Drug Group & References \\
\hline [104] & GSK2033 & & \\
\hline
\end{tabular}

endogenous LXR agonist, increases ABCA1 expression and cholesterol efflux. ${ }^{98}$ The LXR agonist LXR-623 (WAY252623) increases ABCA1 expression and cholesterol efflux and does not change hepatic lipid metabolism. LXR-623 was the first LXR-targeting compound to be evaluated in clinical trials, and no deaths or serious adverse events were reported. ${ }^{99}$ LXR antagonists, including SR9238, SR9243, GSK2033, triphenyl phosphate (TPHP), and 2-ethylhexyl diphenyl phosphate (EHDPP), inhibited cholesterol efflux and promoted atherosclerotic lesion formation in mice (Table 1). TPHP and EHDPP have been detected in indoor dust, especially TPHP, which is one of the most predominant pollutants with concentrations as high as $20,700 \mu \mathrm{g} / \mathrm{g} .{ }^{100}$ Therefore, we should be aware that indoor dust can be a cardiovascular hazard. Nevertheless, some LXR-targeting compounds are beneficial. For example, SR9238 reduced hepatic lipogenesis in models of obesity and hepatic steatosis, ${ }^{101,102}$ and SR9243 suppressed intrahepatic inflammation and fibrosis in patients with nonalcoholic steatohepatitis. ${ }^{103,104}$ These beneficial compounds usually require liver specificity to avoid causing potential detrimental effects on RCT in peripheral tissues. These results suggest that ABCA1 is a therapeutic target of atherosclerosis.

\section{Drugs Targeting APEI/Ref-I}

DrugBank shows that APE1/Ref-1 is a target of numerous drugs, including lucanthone and the APE1/Ref-1 inhibitors APX3330 (E3330), APX2009, APX2014, gossypol, inhibitor III, endonuclease inhibitor (compound \#3), RN7-60, RN8-51, RN10-52, MC043, MC047, MC042, MC019, compound 13, compound 21, compound 23, and compound 24 (Table 2). APX3330, a

Table 2 APEI/Ref-I is a Therapeutic Drug Target

\begin{tabular}{|c|c|c|c|c|c|}
\hline Type & Name & Structure & $I C_{50}(\mu M)$ & Drug Group & References \\
\hline & Lucanthone & & & Investigational & DrugBank \\
\hline
\end{tabular}

(Continued) 
Table 2 (Continued).

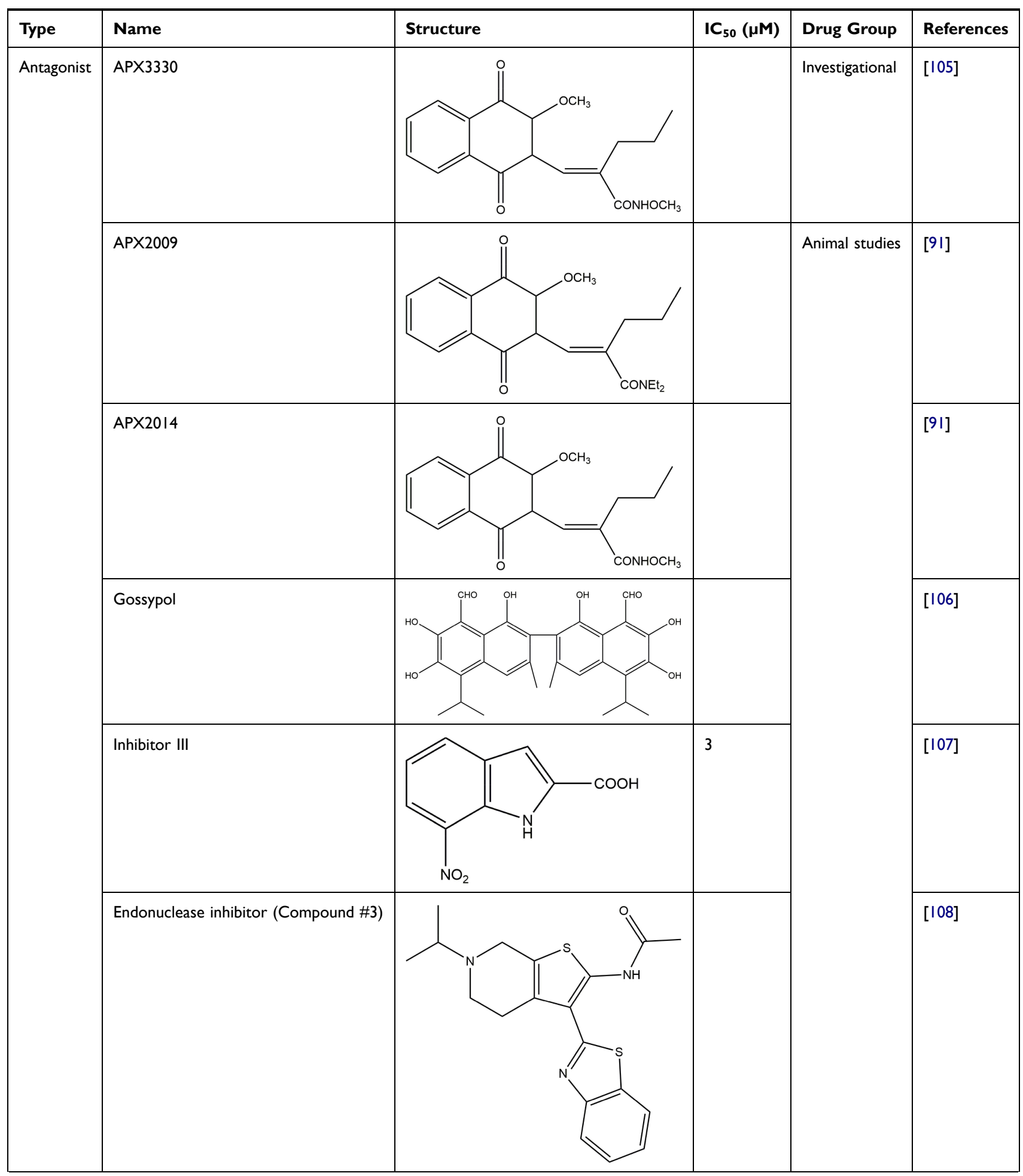

(Continued) 
Table 2 (Continued).

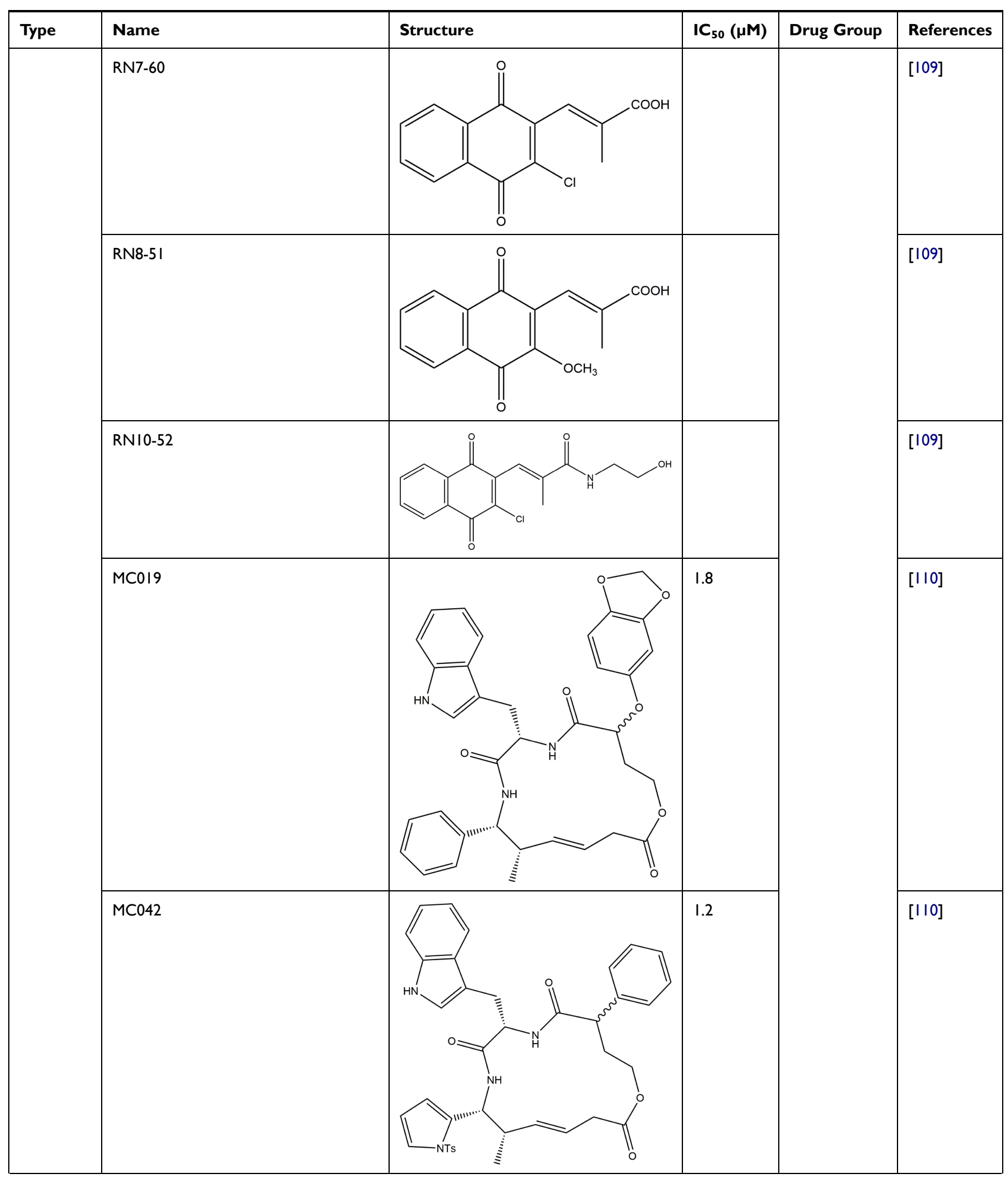

(Continued) 
Table 2 (Continued).

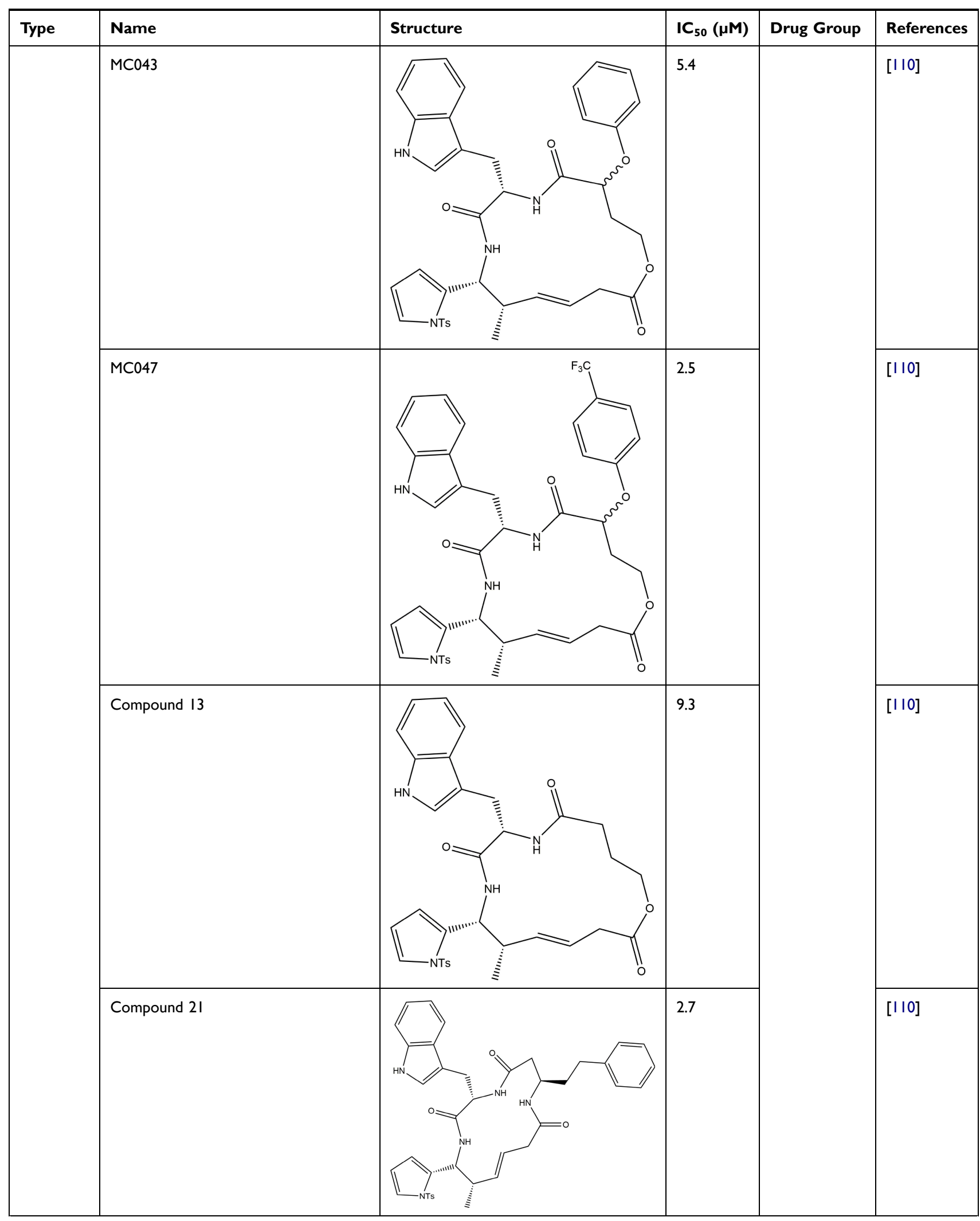

(Continued) 
Table 2 (Continued).

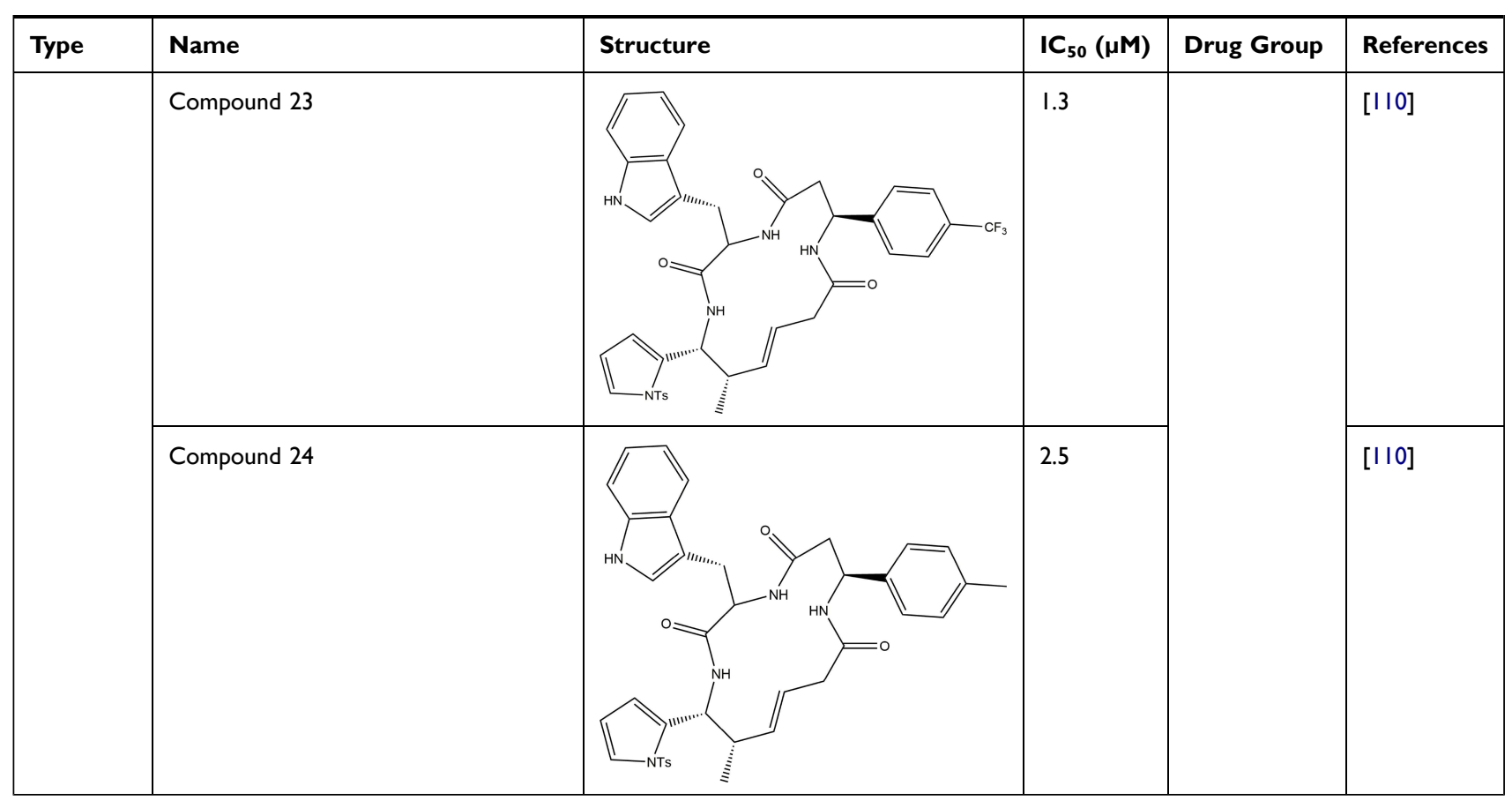

potential inhibitor of solid tumors, is currently being investigated in a phase II clinical trial. ${ }^{105}$ APX2009 and APX2014, which are currently under development, are potentially the most potent second-generation compounds. ${ }^{91}$ Gossypol in combination with docetaxel and cisplatin improved the efficacy of chemotherapy for advanced non-small-cell lung cancer (NSCLC). ${ }^{106}$ Inhibitor III showed substantial antileukemic efficacy, ${ }^{107}$ and compound \#3 affected mitochondrial activity and suppressed colorectal cancer. ${ }^{108}$ RN7-60 and RN10-52 had a greater effect than APX3330 on ovarian cancer cells, and RN8-51 had an effect similar to that of APX3330. However, unlike RN7-60 and RN10-52, APX3330 and RN8-51 did not induce the apoptosis of umbilical cord blood-derived erythroid-colony-forming cells (ECFCs), suggesting that RN8-51 has potential as a cancer therapeutic. ${ }^{109}$ The IC50 values of MC043, MC047, MC042, MC019, compound 13, compound 21, compound 23, and compound 24 were $5.4,2.5,1.2,1.8$, 9.3, 2.7, 1.3, and $2.5 \mu \mathrm{M}$, respectively, and the EC50 values for all these compounds were $>100 \mu \mathrm{M} .{ }^{110}$ These results suggest that APE1/Ref-1 is a therapeutic target in cancer. However, the function of APE1/Ref-1 inhibitors in atherosclerosis is minimal, and more studies are needed.

\section{The ABCAI-APEI/Ref-I Axis: A Potential Therapeutic Target for Atherosclerosis}

As mentioned above, ABCA1 is a therapeutic target in atherosclerosis that enhances cholesterol efflux, antiinflammatory responses, and apoptotic cell clearance. AcAPE1/Ref-1 is a therapeutic target in cancer and decreases the development of atherosclerosis by enhancing anti-inflammatory effects and DNA damage repair. ${ }^{11}$ ABCA1 controls the secretion of AcAPE1/ Ref-1, and together, these proteins form the ABCA1APE1/Ref-1 axis. Based on these results, we hypothesize that the ABCA1-APE1/Ref-1 axis is a potential therapeutic target for atherosclerosis. However, further studies are needed.

\section{Summary}

Atherosclerotic cardiovascular disease is the leading cause of death worldwide. ${ }^{112,113}$ APE1/Ref-1 plays dual roles in atherosclerosis and is a potential biomarker of CAD. However, biomarkers should be sensitive and specific for diagnosing the disease state. Additional larger studies are needed before APE1/Ref-1 can be clinically used as a novel biomarker for the early diagnosis and prognostic prediction of CAD. Notably, early studies and computer analysis via the GeneCards database 


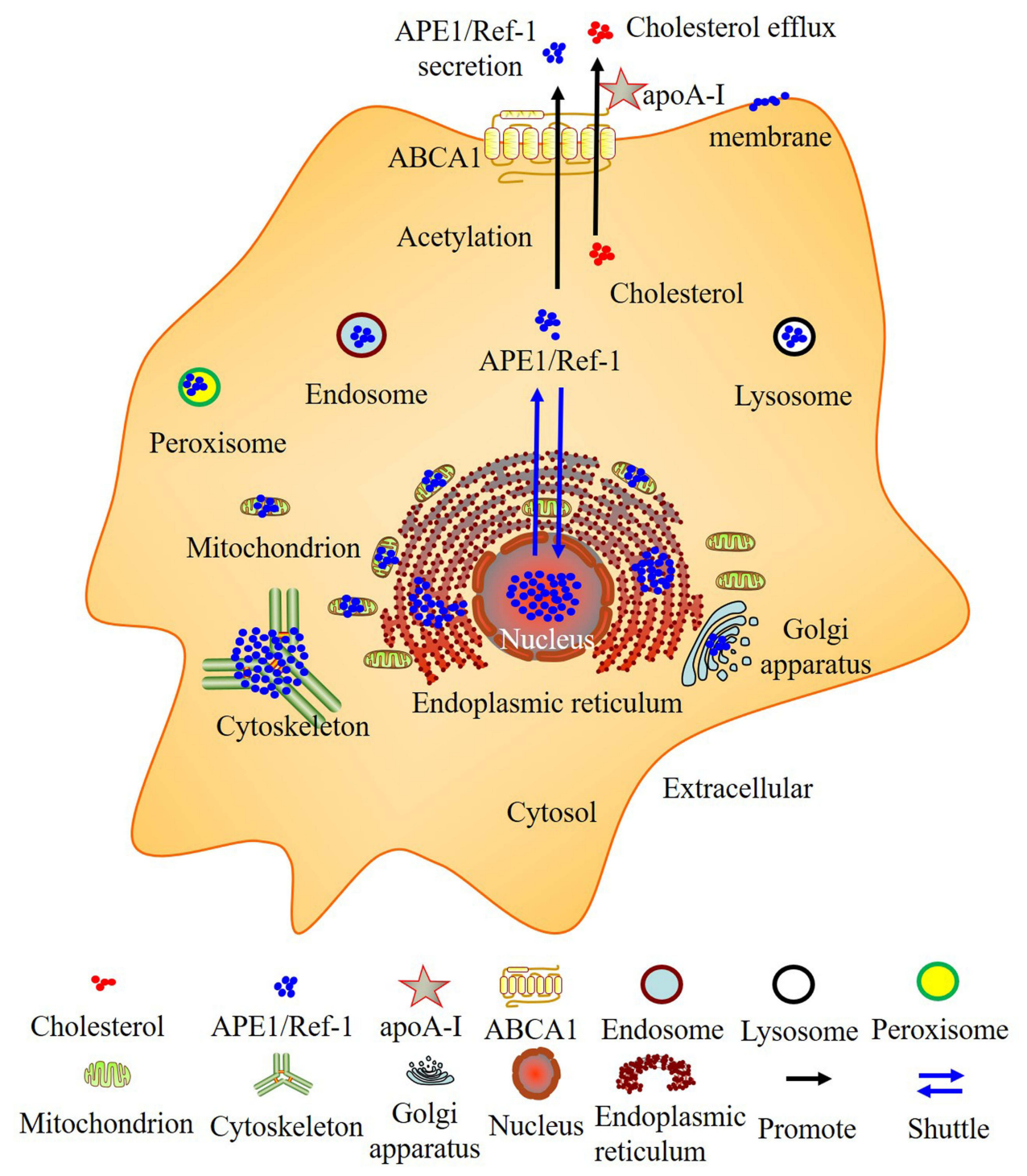

Figure 3 The subcellular localization of APEI/Ref-I and ABCAI is responsible for both cholesterol efflux and APEI/Ref-I secretion. Computational analysis of the subcellular localization of human APEI/Ref-I using GeneCards (https://www.genecards.org/). APEI/Ref-I was detected in not only the nucleus but also other compartments, including the cytoskeleton, plasma membrane, etc. The extracellular secretion of APEI/Ref-I depends on its acetylation. ABCAI is responsible for both cholesterol efflux and acetylated APEI/Ref-I secretion.

have shown that APE1/Ref-1 is localized in the nucleus, cytoplasm, and mitochondria and is even secreted from the cell (Figure 3). Under basal conditions, APE1/Ref-1 is localized in the nucleus; localization of this protein is dynamically regulated by the disease state, which can evoke cytoplasmic/mitochondrial translocation or extracellular secretion, potentially leading to the proatherogenic and antiatherogenic effects of APE1/Ref-1. Cellor tissue-specific APE1/Ref-1 localization may also play dual roles in atherosclerosis. ${ }^{114}$ APE1/Ref-1 is highly expressed in the cells of patients with atherosclerosis to protect against hypoxic injury in tissues, and the secretion of AcAPE1/Ref-1 is a treatment target in atherosclerosis. However, larger studies, such as those involving knockout experiments, GWAS and exome sequencing, are needed to determine whether APE1/ Ref-1 is proatherogenic or antiatherogenic. In addition, ABCA1 is responsible for not only cholesterol efflux and anti-inflammatory effects but also the secretion of AcAPE1/Ref-1 (Figure 3). However, the effect of the ABCA1-APE1/Ref-1 axis on atherosclerosis is unclear, and more studies are needed. The APE1/Ref-1 inhibitor APX3330 is being evaluated in a phase II clinical trial, and the ABCA1/LXR agonist LXR-623 (WAY-252623) has been evaluated in clinical trials. We sincerely hope that more scientists will study the role of the ABCA1- 
APE1/Ref-1 axis in atherosclerosis to identify potential biomarkers and novel therapeutic targets.

\section{Abbreviations}

MI, myocardial infarction; $\mathrm{CAD}$, coronary artery disease; ABCA1, ATP-binding cassette transporter A1; apoA-I, apolipoprotein A-I; APE1/APE1/Ref-1, apurinic (apyrimidinic) endonuclease-1/redox factor-1; AP-1, activator protein-1; $\mathrm{NF}-\kappa \mathrm{B}$, nuclear factor $\kappa \mathrm{B}$; BER, base excision repair; ROS, reactive oxygen species; VSMCs, vascular smooth muscle cells; VCAM-1, vascular cell adhesion molecule-1; TNF- $\alpha$, tumor necrosis factor $\alpha$; HUVECs, human umbilical vein endothelial cells; IL-6, interleukin-6; Ang II, angiotensin II; RASMCs, rat aortic smooth muscle cells; S1PR1, sphingosine-1-phosphate receptor; Hcy, homocysteine; MCP-1, monocyte chemoattractant protein-1; HHcy, hyperhomocysteinemia; Trx1, thioredoxin 1; ECs, endothelial cells; Arg-1, arginase-1; TGF- $\beta$, transforming growth factor $\beta$; AP, apurinic/apyrimidinic; LPS, lipopolysaccharide; WD, Western diet; NLR, neutrophil/lymphocyte ratio; NT-proBNP, $\mathrm{N}$-terminal pro-B type natriuretic peptide; CRP, C-reactive protein; EF, ejection fraction; SNP, single nucleotide polymorphism; HDL, high-density lipoprotein; RCT, reverse cholesterol transport; GM-CSF, granulocyte macrophage colony-stimulating factor; MIF, migration inhibitory factor; IL-1 $\beta$, interleukin-1 beta; ANXA1, annexin A1; PrCR, programmed cell removal; PtdSer, phosphatidylserine; MEGF10, multiple EGF-like domains 10; GULP1, engulfment adaptor phosphotyrosine-binding domain (PTB) domain containing 1; TG2, transglutaminase 2; HDAC, histone deacetylase; TSA, trichostatin A; TPHP, triphenyl phosphate; EHDPP, 2-ethylhexyl diphenyl phosphate; ECFCs, erythroid-colony-forming cells.

\section{Acknowledgments}

We thank Dr. Dongming Xing's laboratory for technical support and stimulating discussions. We thank you for Ning Liu and Xiaodan $\mathrm{Xu}$ guidance during the revision process. All authors thank AJE for English polishing.

\section{Funding}

The authors are grateful for financial support from the Qingdao Major Scientific and Technological Project for Distinguished Scholars (20170103), the Laoshan Major Scientific and Technological Project for Distinguished Scholars (20181030), the Natural Science Foundation of Shandong Province (ZR2020MH242, ZR2020MH369).

\section{Disclosure}

The authors declare no conflicts of interest associated with this paper.

\section{References}

1. Libby P. The changing landscape of atherosclerosis. Nature. 2021;592:524-533. doi:10.1038/s41586-021-03392-8

2. Libby P, Buring JE, Badimon L, et al. Atherosclerosis. Nat Rev Dis Primers. 2019;5:56. doi:10.1038/s41572-019-0106-Z

3. Weber C, Noels H. Atherosclerosis: current pathogenesis and therapeutic options. Nat Med. 2011;17:1410-1422. doi:10.1038/ nm. 2538

4. Phang SW, Ooi BK, Ahemad N, Yap WH. Maslinic acid suppresses macrophage foam cells formation: regulation of monocyte recruitment and macrophage lipids homeostasis. Vascul Pharmacol. 2020;128-129:106675. doi:10.1016/j.vph.2020.106 675

5. Frambach S, de Haas R, Smeitink JAM, Rongen GA, Russel FGM, Schirris TJJ. Brothers in arms: ABCA1- and ABCG1mediated cholesterol efflux as promising targets in cardiovascular disease treatment. Pharmacol Rev. 2020;72:152-190. doi:10.11 24/pr.119.017897

6. Koga M, Kanaoka Y, Inada K, Omine S, Kataoka Y, Yamauchi A. Hesperidin blocks varenicline-aggravated atherosclerotic plaque formation in apolipoprotein $\mathrm{E}$ knockout mice by downregulating net uptake of oxidized low-density lipoprotein in macrophages. $J$ Pharmacol Sci. 2020;143:106-111. doi:10.1016/j.jphs.2020.01.012

7. Zhang S, Li L, Wang J, et al. Recent advances in the regulation of ABCA1 and ABCG1 by lncRNAs. Clin Chim Acta. 2021;51 6:100-110. doi:10.1016/j.cca.2021.01.019

8. Yin K, Chen WJ, Zhou ZG, et al. Apolipoprotein A-I inhibits CD40 proinflammatory signaling via ATP-binding cassette transporter A1-mediated modulation of lipid raft in macrophages. $J$ Atheroscler Thromb. 2012;19:823-836. doi:10.5551/jat.12823

9. Babashamsi MM, Koukhaloo SZ, Halalkhor S, Salimi A, Babashamsi M. ABCA1 and metabolic syndrome; a review of the ABCA1 role in HDL-VLDL production, insulin-glucose homeostasis, inflammation and obesity. Diabetes Metab Syndr. 2019;13:1529-1534. doi:10.1016/j.dsx.2019.03.004

10. Wang N, Silver DL, Thiele C, Tall AR. ATP-binding cassette transporter $\mathrm{A} 1$ (ABCA1) functions as a cholesterol efflux regulatory protein. J Biol Chem. 2001;276:23742-23747. doi:10.1074/ jbc.M102348200

11. Westerterp M, Fotakis $P$, Ouimet $M$, et al. Cholesterol efflux pathways suppress inflammasome activation, NETosis, and atherogenesis. Circulation. 2018;138:898-912. doi:10.1161/ CIRCULATIONAHA.117.032636

12. Whitaker AM, Stark WJ, Flynn TS, Freudenthal BD. Molecular and structural characterization of disease-associated APE1 polymorphisms. DNA Repair. 2020;91-92:102867. doi:10.1016/j. dnarep.2020.102867

13. Uddin MA, Akhter MS, Siejka A, Catravas JD, Barabutis N. P53 supports endothelial barrier function via APE1/Ref1 suppression. Immunobiology. 2019;224:532-538. doi:10.1016/j.imbio.2019.04. 008

14. Jin SA, Seo HJ, Kim SK, et al. Elevation of the serum apurinic/ apyrimidinic endonuclease 1/Redox factor-1 in coronary artery disease. Korean Circ J. 2015;45:364-371. doi:10.4070/kcj.2015. 45.5.364

15. Chen W, Wu Y, Lu Q, Wang S, Xing D. Endogenous ApoA-I expression in macrophages: a potential target for protection against atherosclerosis. Clin Chim Acta. 2020;505:55-59. doi:10. 1016/j.cca.2020.02.025 
16. Lee YR, Joo HK, Lee EO, et al. ATP binding cassette transporter A1 is involved in extracellular secretion of acetylated APE1/Ref1. Int J Mol Sci. 2019;20:3178.

17. Lee DY, Won KJ, Lee KP, et al. Angiotensin II facilitates neointimal formation by increasing vascular smooth muscle cell migration: involvement of APE/Ref-1-mediated overexpression of sphingosine-1-phosphate receptor 1. Toxicol Appl Pharmacol. 2018;347:45-53. doi:10.1016/j.taap.2018.03.032

18. Lee KM, Lee EO, Lee YR, et al. APE1/Ref-1 inhibits phosphateinduced calcification and osteoblastic phenotype changes in vascular smooth muscle cells. Int J Mol Sci. 2017;18(10):2053. doi:10.3390/ijms18102053

19. Park MS, Choi S, Lee YR, et al. Secreted APE1/Ref-1 inhibits TNFalpha-stimulated endothelial inflammation via thiol-disulfide exchange in TNF receptor. Sci Rep. 2016;6:23015. doi:10.1038/ srep23015

20. Martinet W, Knaapen MW, De Meyer GR, Herman AG, Kockx MM. Elevated levels of oxidative DNA damage and DNA repair enzymes in human atherosclerotic plaques. Circulation. 2002;106:927-932. doi:10.1161/01.CIR.0000026393.47805.21

21. Godschalk RW, Albrecht C, Curfs DM, et al. Decreased levels of lipid peroxidation-induced DNA damage in the onset of atherogenesis in apolipoprotein $\mathrm{E}$ deficient mice. Mutat Res. 2007;621:87-94. doi:10.1016/j.mrfmmm.2007.02.012

22. Thakur S, Sarkar B, Cholia RP, Gautam N, Dhiman M, Mantha AK. APE1/Ref-1 as an emerging therapeutic target for various human diseases: phytochemical modulation of its functions. Exp Mol Med. 2014;46:e106.

23. Jacinto TA, Meireles GS, Dias AT, et al. Increased ROS production and DNA damage in monocytes are biomarkers of aging and atherosclerosis. Biol Res. 2018;51:33. doi:10.1186/s40659-018-0182-7

24. Shah A, Gray K, Figg N, Finigan A, Starks L, Bennett M. Defective base excision repair of oxidative DNA damage in vascular smooth muscle cells promotes atherosclerosis. Circulation. 2018;138:14461462. doi:10.1161/CIRCULATIONAHA.117.033249

25. Joshi NV, Elkhawad M, Forsythe RO, et al. Greater aortic inflammation and calcification in abdominal aortic aneurysmal disease than atherosclerosis: a prospective matched cohort study. Open Heart. 2020;7:e001141. doi:10.1136/openhrt-2019-001141

26. Kojima Y, Ye J, Nanda V, et al. Knockout of the murine ortholog to the human 9 p21 coronary artery disease locus leads to smooth muscle cell proliferation, vascular calcification, and advanced atherosclerosis. Circulation. 2020;141:1274-1276. doi:10.1161/ CIRCULATIONAHA.119.043413

27. Baek H, Lim CS, Byun HS, et al. The anti-inflammatory role of extranuclear apurinic/apyrimidinic endonuclease 1/redox effector factor-1 in reactive astrocytes. Mol Brain. 2016;9:99. doi:10. 1186/s13041-016-0280-9

28. Bazlekowa-Karaban M, Prorok P, Baconnais S, et al. Mechanism of stimulation of DNA binding of the transcription factors by human apurinic/apyrimidinic endonuclease 1, APE1. DNA Repair. 2019;82:102698. doi:10.1016/j.dnarep.2019.102698

29. Kim CS, Son SJ, Kim EK, et al. Apurinic/apyrimidinic endonuclease1/redox factor-1 inhibits monocyte adhesion in endothelial cells. Cardiovasc Res. 2006;69:520-526. doi:10.1016/j.cardiores. 2005.10.014

30. Hall JL, Wang $\mathrm{X}$, Adamson V, Zhao Y, Gibbons GH. Overexpression of Ref-1 inhibits hypoxia and tumor necrosis factor-induced endothelial cell apoptosis through nuclear factorkappab-independent and -dependent pathways. Circ Res. 2001;88:1247-1253. doi:10.1161/hh1201.091796

31. Lee HM, Jeon BH, Won KJ, et al. Gene transfer of redox factor-1 inhibits neointimal formation: involvement of platelet-derived growth factor-beta receptor signaling via the inhibition of the reactive oxygen species-mediated Syk pathway. Circ Res. 2009;104:219-227, 215p following 227. doi:10.1161/CIRCRESAHA.108.178699
32. Hu Z, Hui B, Hou X, Liu R, Sukhanov S, Liu X. APE1 inhibits foam cell formation from macrophages via LOX1 suppression. Am J Transl Res. 2020;12:6559-6568.

33. Zhang Y, Wang Y, Zhou D, et al. Angiotensin II deteriorates advanced atherosclerosis by promoting MerTK cleavage and impairing efferocytosis through the AT1R/ROS/p38 MAPK/ ADAM17 pathway. Am J Physiol Cell Physiol. 2019;317:C776C787. doi:10.1152/ajpcell.00145.2019

34. Braz NFT, Pinto MRC, Vieira ELM, et al. Renin-angiotensin system molecules are associated with subclinical atherosclerosis and disease activity in rheumatoid arthritis. Mod Rheumatol. 2021;31:119-126.

35. Fukuda D, Nishimoto S, Aini K, et al. Toll-like receptor 9 plays a pivotal role in angiotensin II-induced atherosclerosis. $J$ Am Heart Assoc. 2019;8:e010860. doi:10.1161/JAHA.118.010860

36. Gonzalez L, Qian AS, Tahir U, Yu P, Trigatti BL. Sphingosine-1phosphate receptor 1 , expressed in myeloid cells, slows dietinduced atherosclerosis and protects against macrophage apoptosis in Ldlr KO mice. Int $J$ Mol Sci. 2017;18(12):2721. doi:10.3390/ijms 18122721

37. Jozefczuk E, Guzik TJ, Siedlinski M. Significance of sphingosine-1-phosphate in cardiovascular physiology and pathology. Pharmacol Res. 2020;156:104793. doi:10.1016/j.phrs.2020.104 793

38. Dai J, Li W, Chang L, et al. Role of redox factor-1 in hyperhomocysteinemia-accelerated atherosclerosis. Free Radic Biol Med. 2006;41:1566-1577. doi:10.1016/j.freeradbiomed.2006.08.020

39. Piazzolla G, Candigliota M, Fanelli $M$, et al. Hyperhomocysteinemia is an independent risk factor of atherosclerosis in patients with metabolic syndrome. Diabetol Metab Syndr. 2019;11:87. doi:10.1186/s13098-019-0484-0

40. Chen B, Guan D, Cui ZJ, Wang X, Shen X. Thioredoxin 1 downregulates MCP-1 secretion and expression in human endothelial cells by suppressing nuclear translocation of activator protein 1 and redox factor-1. Am J Physiol Cell Physiol. 2010;298:C1170-1179. doi:10.1152/ajpcell.00223.2009

41. Hadri KE, Mahmood DF, Couchie D, et al. Thioredoxin-1 promotes anti-inflammatory macrophages of the M2 phenotype and antagonizes atherosclerosis. Arterioscler Thromb Vasc Biol. 2012;32:1445-1452. doi:10.1161/ATVBAHA.112.249334

42. Barrett TJ. Macrophages in atherosclerosis regression. Arterioscler Thromb Vasc Biol. 2020;40:20-33. doi:10.1161/ ATVBAHA.119.312802

43. Chang SF, Chang PY, Chou YC, Lu SC. Electronegative LDL induces M1 polarization of human macrophages through a LOX1-dependent pathway. Inflammation. 2020;43(4):1524-1535. doi:10.1007/s10753-020-01229-6

44. Canesi F, Mateo V, Couchie D, et al. A thioredoxin-mimetic peptide exerts potent anti-inflammatory, antioxidant, and atheroprotective effects in ApoE2.Ki mice fed high fat diet. Cardiovasc Res. 2019;115:292-301. doi:10.1093/cvr/cvy183

45. Madrigal-Matute J, Fernandez-Garcia CE, Blanco-Colio LM, et al. Thioredoxin-1/peroxiredoxin-1 as sensors of oxidative stress mediated by NADPH oxidase activity in atherosclerosis. Free Radic Biol Med. 2015;86:352-361. doi:10.1016/j.freeradbiomed.2015.06.001

46. Wang X, Zhao H, Yan W, et al. Thioredoxin-1 promotes macrophage reverse cholesterol transport and protects liver from steatosis. Biochem Biophys Res Commun. 2019;516:1103-1109. doi:10.1016/j.bbrc.2019.06.109

47. Kwon DH, Ryu J, Kim YK, Kook H. Roles of histone acetylation modifiers and other epigenetic regulators in vascular calcification. Int J Mol Sci. 2020;21(9):3246. doi:10.3390/ijms21093246

48. Nicorescu I, Dallinga GM, de Winther MPJ, Stroes ESG, Bahjat M. Potential epigenetic therapeutics for atherosclerosis treatment. Atherosclerosis. 2019;281:189-197. doi:10.1016/j.atherosclerosis. 2018.10.006 
49. Roychoudhury S, Pramanik S, Harris HL, Bhakat KK. Biochemical and cellular assays to assess the effects of acetylation on base excision repair enzymes. Methods Mol Biol. 2019;1983:191-206.

50. Lirussi L, Antoniali G, Scognamiglio PL, et al. Cleavage of the APE1 N-terminal domain in acute myeloid leukemia cells is associated with proteasomal activity. Biomolecules. 2020;10 (4):531. doi:10.3390/biom10040531

51. Roychoudhury S, Nath S, Song H, et al. Human apurinic/apyrimidinic endonuclease (APE1) is acetylated at DNA damage sites in chromatin, and acetylation modulates its DNA repair activity. Mol Cell Biol. 2017;37. doi:10.1128/MCB.00401-16

52. Roychoudhury S, Pramanik S, Harris HL, et al. Endogenous oxidized DNA bases and APE1 regulate the formation of G-quadruplex structures in the genome. Proc Natl Acad Sci U S A. 2020;117:11409-11420. doi:10.1073/pnas.1912355117

53. Joo HK, Lee YR, Lee EO, et al. The extracellular role of Ref-1 as anti-inflammatory function in lipopolysaccharide-induced septic mice. Free Radic Biol Med. 2019;139:16-23. doi:10.1016/j. freeradbiomed.2019.05.013

54. Bhakat KK, Mantha AK, Mitra S. Transcriptional regulatory functions of mammalian AP-endonuclease (APE1/Ref-1), an essential multifunctional protein. Antioxid Redox Signal. 2009;11:621-638. doi:10.1089/ars.2008.2198

55. Lee YR, Joo HK, Lee EO, et al. Plasma APE1/Ref-1 correlates with atherosclerotic inflammation in ApoE(-/-) mice. Biomedicines. 2020;8(9):366. doi:10.3390/biomedicines8090366

56. Skarpengland T, Laugsand LE, Janszky I, et al. Genetic variants in the DNA repair gene NEIL3 and the risk of myocardial infarction in a nested case-control study. The HUNT Study. DNA Repair (Amst). 2015;28:21-27. doi:10.1016/j.dnarep.20 15.01 .013

57. Jin SA, Lim BK, Seo HJ, et al. Elevation of serum APE1/Ref-1 in experimental murine myocarditis. Int $J$ Mol Sci. 2017;18 (12):2664. doi:10.3390/ijms 18122664

58. Chen W, Li L, Wang J, et al. Extracellular vesicle YRNA in atherosclerosis. Clin Chim Acta. 2021;517:15-22. doi:10.1016/j. cca.2021.02.003

59. Wu Y, Li Q, Zhang R, Dai X, Chen W, Xing D. Circulating microRNAs: biomarkers of disease. Clin Chim Acta. 2021;516:46-54. doi:10.1016/j.cca.2021.01.008

60. Wu Y, Cui S, Li Q, et al. Recent advances in duplex-specific nuclease-based signal amplification strategies for microRNA detection. Biosens Bioelectron. 2020;165:112449. doi:10.1016/j. bios.2020.112449

61. Chen WJ, Zhang M, Zhao GJ, et al. MicroRNA-33 in atherosclerosis etiology and pathophysiology. Atherosclerosis. 2013;227:201-208. doi:10.1016/j.atherosclerosis.2012.11.025

62. Tang SL, Chen WJ, Yin K, et al. PAPP-A negatively regulates ABCA1, ABCG1 and SR-B1 expression by inhibiting LXRalpha through the IGF-I-mediated signaling pathway. Atherosclerosis. 2012;222:344-354. doi:10.1016/j.atherosclerosis.2012.03.005

63. Chen WJ, Yin K, Zhao GJ, Fu YC, Tang CK. The magic and mystery of microRNA-27 in atherosclerosis. Atherosclerosis. 2012;222:314-323. doi:10.1016/j.atherosclerosis.2012.01.020

64. Tian GP, Chen WJ, He PP, et al. MicroRNA-467b targets LPL gene in RAW 264.7 macrophages and attenuates lipid accumulation and proinflammatory cytokine secretion. Biochimie. 2012;94:2749-2755. doi:10.1016/j.biochi.2012.08.018

65. Chen W, Zhang S, Wu J, et al. Butyrate-producing bacteria and the gut-heart axis in atherosclerosis. Clin Chim Acta. 2020;507:236-241. doi:10.1016/j.cca.2020.04.037

66. Cheng W, Yan K, Chen Y, Zhang W, Ji Z, Dang C. ABCA1 inhibits PDGF-induced proliferation and migration of rat airway smooth muscle cell through blocking TLR2/NF-kappaB/NFATc1 signaling. J Cell Biochem. 2018;119:7388-7396. doi:10.1002/jcb.27046
67. Chistiakov DA, Grechko AV, Myasoedova VA, Melnichenko AA, Orekhov AN. The role of monocytosis and neutrophilia in atherosclerosis. J Cell Mol Med. 2018;22:1366-1382. doi:10.1111/ jcmm. 13462

68. Wang N, Westerterp M. ABC transporters, cholesterol efflux, and implications for cardiovascular diseases. Adv Exp Med Biol. 2020;1276:67-83.

69. Kuang HJ, Zhao GJ, Chen WJ, et al. Hsp27 promotes ABCA1 expression and cholesterol efflux through the PI3K/PKCzeta/Sp1 pathway in THP-1 macrophages. Eur J Pharmacol. 2017;810:5762. doi:10.1016/j.ejphar.2017.06.015

70. Price NL, Rotllan N, Zhang X, et al. Specific disruption of Abca1 targeting largely mimics the effects of miR-33 knockout on macrophage cholesterol efflux and atherosclerotic plaque development. Circ Res. 2019;124:874-880. doi:10.1161/ CIRCRESAHA.118.314415

71. Flieger O, Engling A, Bucala R, Lue H, Nickel W, Bernhagen J. Regulated secretion of macrophage migration inhibitory factor is mediated by a non-classical pathway involving an $\mathrm{ABC}$ transporter. FEBS Lett. 2003;551:78-86. doi:10.1016/S0014-5793(03) 00900-1

72. Hamon Y, Luciani MF, Becq F, Verrier B, Rubartelli A, Chimini G. Interleukin-1beta secretion is impaired by inhibitors of the Atp binding cassette transporter, ABC1. Blood. 1997;90:2911-2915. doi:10.1182/blood.V90.8.2911

73. Jacobo-Albavera L, Dominguez-Perez M, Medina-Leyte DJ, Gonzalez-Garrido A, Villarreal-Molina T. The role of the ATPBinding Cassette A1 (ABCA1) in human disease. Int J Mol Sci. 2021;22(4):1593. doi:10.3390/ijms22041593

74. Shen X, Zhang S, Guo Z, Xing D, Chen W. The crosstalk of ABCA1 and ANXA1: a potential mechanism for protection against atherosclerosis. Mol Med. 2020;26:84. doi:10.1186/ s10020-020-00213-y

75. Wang S, Gulshan K, Brubaker G, Hazen SL, Smith JD. ABCA1 mediates unfolding of apolipoprotein AI $\mathrm{N}$ terminus on the cell surface before lipidation and release of nascent high-density lipoprotein. Arterioscler Thromb Vasc Biol. 2013;33:1197-1205. doi:10.1161/ATVBAHA.112.301195

76. Krimbou L, Denis M, Haidar B, Carrier M, Marcil M, Genest J Jr. Molecular interactions between apoE and ABCA1: impact on apoE lipidation. J Lipid Res. 2004;45:839-848. doi:10.1194/jlr. M300418-JLR200

77. Duong PT, Collins HL, Nickel M, Lund-Katz S, Rothblat GH, Phillips MC. Characterization of nascent HDL particles and microparticles formed by ABCA1-mediated efflux of cellular lipids to apoA-I. J Lipid Res. 2006;47:832-843. doi:10.1194/j1r. M500531-JLR200

78. Nandi S, Ma L, Denis M, et al. ABCA1-mediated cholesterol efflux generates microparticles in addition to HDL through processes governed by membrane rigidity. J Lipid Res. 2009;50:456466. doi:10.1194/jlr.M800345-JLR200

79. Hafiane A, Genest J. ATP binding cassette A1 (ABCA1) mediates microparticle formation during high-density lipoprotein (HDL) biogenesis. Atherosclerosis. 2017;257:90-99. doi:10.1016/j. atherosclerosis.2017.01.013

80. Ma L, Dong F, Denis M, Feng Y, Wang MD, Zha X. Ht31, a protein kinase A anchoring inhibitor, induces robust cholesterol efflux and reverses macrophage foam cell formation through ATP-binding cassette transporter A1. J Biol Chem. 2011;286:3370-3378. doi:10.1074/jbc.M110. 173666

81. Jerez-Dolz D, Torramade-Moix S, Palomo $\mathrm{M}$, et al. Internalization of microparticles by platelets is partially mediated by toll-like receptor 4 and enhances platelet thrombogenicity. Atherosclerosis. 2020;294:17-24. doi:10.1016/j.atherosclerosis. 2019.12.017 
82. Rogula S, Gasecka A, Filipiak KJ. Macroscopic role of microparticles in cardiovascular disease. Pol Merkur Lekarski. 2020;49:255-259.

83. Chen YT, Yuan HX, Ou ZJ, Ou JS. Microparticles (Exosomes) and atherosclerosis. Curr Atheroscler Rep. 2020;22:23. doi:10.1007/s11883-020-00841-z

84. Sharma M, Schlegel MP, Afonso MS, et al. Regulatory T cells license macrophage pro-resolving functions during atherosclerosis regression. Circ Res. 2020;127:335-353. doi:10.1161/ CIRCRESAHA.119.316461

85. Tabas I, Bornfeldt KE. Intracellular and intercellular aspects of macrophage immunometabolism in atherosclerosis. Circ Res. 2020;126:1209-1227. doi:10.1161/CIRCRESAHA.119.315939

86. Chen W, Li L, Wang J, et al. The ABCA1-efferocytosis axis: a new strategy to protect against atherosclerosis. Clin Chim Acta. 2021;518:1-8. doi:10.1016/j.cca.2021.02.025

87. Hamon Y, Broccardo C, Chambenoit O, et al. $\mathrm{ABC} 1$ promotes engulfment of apoptotic cells and transbilayer redistribution of phosphatidylserine. Nat Cell Biol. 2000;2:399-406. doi:10.1038/ 35017029

88. Morizawa YM, Hirayama Y, Ohno N, et al. Reactive astrocytes function as phagocytes after brain ischemia via ABCA1-mediated pathway. Nat Commun. 2017;8:28. doi:10.1038/s41467-017-00037-1

89. Iadevaia V, Rinaldi A, Falasca L, et al. ATP-binding cassette transporter 1 and transglutaminase 2 act on the same genetic pathway in the apoptotic cell clearance. Cell Death Differ. 2006;13:1998-2001. doi:10.1038/sj.cdd.4401930

90. Tournier N, Saba W, Cisternino S, et al. Effects of selected OATP and/or $\mathrm{ABC}$ transporter inhibitors on the brain and whole-body distribution of glyburide. AAPS J. 2013;15:1082-1090.

91. Fishel ML, Xia H, McGeown J, et al. Antitumor activity and mechanistic characterization of APE1/Ref-1 inhibitors in bladder cancer. Mol Cancer Ther. 2019;18:1947-1960. doi:10.1158/15357163.MCT-18-1166

92. Luo F, Guo Y, Ruan G, Li X. Metformin promotes cholesterol efflux in macrophages by up-regulating FGF21 expression: a novel anti-atherosclerotic mechanism. Lipids Health Dis. 2016;15:109. doi:10.1186/s12944-016-0281-9

93. Argmann CA, Edwards JY, Sawyez CG, et al. Regulation of macrophage cholesterol efflux through hydroxymethylglutarylCoA reductase inhibition: a role for RhoA in ABCA1-mediated cholesterol efflux. J Biol Chem. 2005;280:22212-22221. doi:10.1074/jbc.M502761200

94. Santovito D, Marcantonio P, Mastroiacovo D, et al. High dose rosuvastatin increases ABCA1 transporter in human atherosclerotic plaques in a cholesterol-independent fashion. Int $J$ Cardiol. 2020;299:249-253. doi:10.1016/j.ijcard.2019.07.094

95. Yu M, Amengual J, Menon A, et al. Targeted nanotherapeutics encapsulating liver X receptor agonist GW3965 enhance antiatherogenic effects without adverse effects on hepatic lipid metabolism in Ldlr -/-Mice. Adv Healthc Mater. 2017;6:1700313. doi:10.1002/adhm.201700313

96. Yasuda T, Grillot D, Billheimer JT, et al. Tissue-specific liver X receptor activation promotes macrophage reverse cholesterol transport in vivo. Arterioscler Thromb Vasc Biol. 2010;30:781-786.

97. Li N, Wang X, Xu Y, et al. Identification of a novel liver X receptor agonist that regulates the expression of key cholesterol homeostasis genes with distinct pharmacological characteristics. Mol Pharmacol. 2017;91:264-276. doi:10.1124/mol.116. 105213

98. Vaidya M, Jentsch JA, Peters S, et al. Regulation of ABCA1mediated cholesterol efflux by sphingosine-1-phosphate signaling in macrophages. J Lipid Res. 2019;60:506-515. doi:10.1194/ jlr.M088443
99. Katz A, Udata C, Ott E, et al. Safety, pharmacokinetics, and pharmacodynamics of single doses of LXR-623, a novel liver $\mathrm{X}$-receptor agonist, in healthy participants. J Clin Pharmacol. 2009;49:643-649. doi:10.1177/0091270009335768

100. Hu W, Jia Y, Kang Q, et al. Screening of house dust from Chinese homes for chemicals with liver $\mathrm{X}$ receptors binding activities and characterization of atherosclerotic activity using an in vitro macrophage cell line and ApoE-/- Mice. Environ Health Perspect. 2019;127:117003. doi:10.1289/EHP5039

101. Griffett K, Welch RD, Flaveny CA, Kolar GR, NeuschwanderTetri BA, Burris TP. The LXR inverse agonist SR9238 suppresses fibrosis in a model of non-alcoholic steatohepatitis. Mol Metab. 2015;4:353-357. doi:10.1016/j.molmet.2015.01.009

102. Sengupta M, Griffett K, Flaveny CA, Burris TP. Inhibition of hepatotoxicity by a LXR inverse agonist in a model of alcoholic liver disease. ACS Pharmacol Transl Sci. 2018;1:50-60. doi:10.1021/acsptsci.8b00003

103. Huang P, Kaluba B, Jiang XL, et al. Liver X receptor inverse agonist SR9243 suppresses nonalcoholic steatohepatitis intrahepatic inflammation and fibrosis. Biomed Res Int. 2018;2018:8071093. doi:10.1155/2018/8071093

104. Toporova L, Grimaldi M, Boulahtouf A, Balaguer P. Assessing the selectivity of FXR, LXRs, CAR, and RORgamma pharmaceutical ligands with reporter cell lines. Front Pharmacol. 2020;11:1122. doi:10.3389/fphar.2020.01122

105. Lou D, Zhu L, Ding H, Dai HY, Zou GM. Aberrant expression of redox protein Ape1 in colon cancer stem cells. Oncol Lett. 2014;7:1078-1082. doi:10.3892/ol.2014.1864

106. Wang Y, Li X, Zhang L, et al. A randomized, double-blind, placebo-controlled study of B-cell lymphoma 2 homology 3 mimetic gossypol combined with docetaxel and cisplatin for advanced non-small cell lung cancer with high expression of apurinic/apyrimidinic endonuclease 1. Invest New Drugs. 2020;38(6):1862-1871. doi:10.1007/s10637-020-00927-0

107. Kohl V, Flach J, Naumann N, et al. Antileukemic efficacy in vitro of talazoparib and APE1 inhibitor III combined with decitabine in myeloid malignancies. Cancers. 2019;11(10):1493. doi:10.3390/ cancers 11101493

108. Codrich M, Comelli M, Malfatti MC, et al. Inhibition of APE1endonuclease activity affects cell metabolism in colon cancer cells via a p53-dependent pathway. DNA Repair (Amst). 2019;82:102675. doi:10.1016/j.dnarep.2019.102675

109. Kelley MR, Luo M, Reed A, et al. Functional analysis of novel analogues of E3330 that block the redox signaling activity of the multifunctional AP endonuclease/redox signaling enzyme APE1/ Ref-1. Antioxid Redox Signal. 2011;14:1387-1401. doi:10.1089/ ars.2010.3410

110. Trilles R, Beglov D, Chen Q, et al. Discovery of macrocyclic inhibitors of apurinic/apyrimidinic endonuclease 1. J Med Chem. 2019;62:1971-1988. doi:10.1021/acs.jmedchem.8b01529

111. Caston RA, Gampala S, Armstrong L, Messmann RA, Fishel ML, Kelley MR. The multifunctional APE1 DNA repair-redox signaling protein as a drug target in human disease. Drug Discov Today. 2021;26:218-228. doi:10.1016/j.drudis.2020.10.015

112. Chen W, Zhong Y, Feng N, Guo Z, Wang S, Xing D. New horizons in the roles and associations of COX-2 and novel natural inhibitors in cardiovascular diseases. Mol Med. 2021;27(1). doi:10.1186/s10020-021-00358-4

113. Chen W, Xing J, Liu X, Wang S, Xing D. The role and transformative potential of IL-19 in atherosclerosis. Cytokine Growth Factor Rev. 2021. doi:10.1016/j.cytogfr.2021.09.001

114. Lee YR, Joo HK, Jeon BH. The biological role of apurinic/ apyrimidinic endonuclease $1 /$ redox factor- 1 as a therapeutic target for vascular inflammation and as a serologic biomarker. Biomedicines. 2020;8(3):57. doi:10.3390/biomedicines 8030057 


\section{Publish your work in this journal}

The Journal of Inflammation Research is an international, peerreviewed open-access journal that welcomes laboratory and clinical findings on the molecular basis, cell biology and pharmacology of inflammation including original research, reviews, symposium reports, hypothesis formation and commentaries on: acute/chronic inflammation; mediators of inflammation; cellular processes; molecular mechanisms; pharmacology and novel anti-inflammatory drugs; clinical conditions involving inflammation. The manuscript management system is completely online and includes a very quick and fair peerreview system. Visit http://www.dovepress.com/testimonials.php to read real quotes from published authors. 